\title{
El campo de la política sanitaria
}

Josep A. Rodríguez*

La dinámica politica contemporánea ha sufrido considerables transformaciones a lo largo de las últimas décadas. Fundamentalmente, el proceso político ya no está ni completa ni exclusivamente estructurado por "arreglos" institucionales formales y se transforma el sistema de representación, perdiendo protagonismo las formas tradicionales de partidos políticos y aumentando su relevancia en la escena política nuevos mecanismos de representación e intermediación (asociaciones, organizaciones, etc.). Estas instituciones se convierten en nuevos vehículos politicos de articulación y representación de intereses. Su papel en la dinámica política se ve realzado tanto por la llamada crisis de las democracias pluralistas y sistemas parlamentarios formales como mecanismos de representación y resolución de conflictos, como por los cambios en la estructura y dinámica social. El aumento de la complejidad social y la consolidación de nuevos sistemas de estratificación y segmentación social, reemplazando la división en dos históricas clases sociales, configuran una amplia clase media con nuevos valores e intereses que requieren de nuevas formas de representación y participación (S. BERGER, 1981). Todo ello configura un nuevo escenario político donde cohabitan las viejas formas de representación, en proceso de redefinición para adaptarse a los nuevos sistemas de segmentación social, con nuevas formas de articulación de intereses parciales. Las nuevas organizaciones centradas en temáticas y áreas sociales especíicas y con una alta capacidad de articulación de discursos coherentes y de cohesión de intereses (parciales) se convierten en los nuevos mecanismos de articulación de intereses y de la acción colectiva.

Se sigue hablando de política y poder en términos de partidos y Parlamentos cuando de hecho la política y el poder se han convertido en algo bastante más complejo. El resultado es un complejo entramado político donde cohabitan organizaciones e instituciones con representación democrática colectiva con organizaciones de representación de intereses parciales (E. LAUMANN y D. KNoKe, 1987; B. Marin y R. MaYNTz, 1991). El espacio político, y el sistema de toma de decisiones políticas, está compuesto por este sistema social de interrelación de ambos ti- pos de organizaciones (D. KNoKe, 1990; J.A. RodRíGuez, 1991) La estructura política resultante es un entramado de redes de acción y presión política. Las redes de interrelación entre organizaciones se convierten en los mecanismos fundamentales de creación de agendas políticas y de acción política. La política deja de ser un espacio de acción individual o uni-organizativo para convertirse en una gran red (de redes) de transmisión de información, creación de coaliciones y alianzas, articulación de presión política, etc. Los tipos de relaciones de las organizaciones y la posición en las estructuras relacionales se traducirán en tipos de acción diferencial y en resultados políticos también diferenciados. Las redes políticas, como el resto de estructuras relacionales, se convierten en vehículos de transmisión de información y recursos y en articuladoras de acción (E. LAUMANN y F. PAPpI, 1976). En tanto que tal tienen efectos limitantes así como efectos potenciadores y posibilitan acceso diferencial a productos y servicios políticos. Las redes políticas hacen referencia a la acción colectiva de actores organizados y, consecuentemente, a las relaciones interorganizativas en el proceso de elaboración de políicas. La estructura de las redes políticas son sistemas interorganizativos y su función es la intervención en la formulación y aplicación de políicas.

Lo que diferencia fundamentalmente a la nueva sociedad y dinámica política no son únicamente las nuevas formas de poder y políica sino la esencia de esas nuevas formas. Vemos cómo se deteriora progresivamente la centralidad de la unidad individual en la acción, en la dinámica social y en el poder sustituidos por la relación-interacción. La relación-interacción se convierte en la piedra angular de nuestra sociedad y ello requiere de los estudiosos nuevas aproximaciones y avenidas analíticas para entender fenómenos que se escapan a las herramientas de base individual que explicaban el mundo en términos del actor racional o de la interiorización de normas como guía de la acción individual (S. WASSERMAN y K. FauST, 1994).

El joven sistema democrático español no únicamente crea las oportunidades sino también la necesidad de creación de ins- 
trumentos de articulación de intereses sectoriales. Como parte misma de la construcción del sistema democrático se inicia un proceso de construcción de organizaciones como articuladores de intereses sectoriales y como vehiculizadores de esos intereses en el proceso político. En el campo sanitario la década de los 80 se caracteriza políticamente, aparte de por la reforma sanitaria socialista, por el intenso proceso de creación de organizaciones de intermediación y la construcción de mecanismos de representación en el proceso políico, que se consolidan durante la década de los 90. La participación de las organizaciones de intereses sanitarios y profesionales en el proceso político de diseño e implantación de políticas sanitarias a lo largo de estas dos décadas se traduce en un sistema complejo de relaciones y alianzas políticas. Alianzas políticas que dan normalmente lugar a coaliciones o actividades conjuntas para aumentar su fortaleza política e incrementar las posibilidades de consecución de sus objetivos políticos.

En las siguientes páginas queremos ofrecer una visión de conjunto del campo político sanitario tanto en términos de la ideología política de los principales actores políticos como en la acción política de las organizaciones de intereses médicos y sanitarios. Mi objetivo es construir un mapa de similitudes políticas y de acción que nos permita entender la globalidad de la dinámica política sanitaria española. Queremos determinar la estructura de los actores y organizaciones en este espacio político, basándonos en la similitud política, en la percepción mutua y en sus pautas de interacción.

\section{Metodología}

Para poder analizar el nuevo y complejo espacio político sanitario utilizamos dos aproximaciones metodológicas: técnicas de análisis espacial (escalado multidimensional) y técnicas de análisis relacional (análisis de redes).

Hemos utilizado técnicas de escalado multidimensional (MDS) con el paquete estadístico SPSS (en la plataforma ASCAL). MDS es una forma matemática de representar el sistema de similitudes y diferencias en una representación gráfica de varias dimensiones. MDS utiliza proximidades entre objetos como input. La proximidad se configura como un número que indica el nivel de similitud o de diferencia entre dos objetos o grupos sociales. El resultado principal es una representación espacial, consistente en una configuración geométrica de puntos, en forma de mapa. Cada punto en la configuración corresponde a uno de los objetos. Esta configuración refleja "la estructura ocultan de los datos. La estructura de los datos significa que a mayor desigualdad (o menor similitud) entre dos objetos, indicada por sus valores de proximidad, mayor es la distancia entre ellos en el mapa espacial (KrusKal y WISH, 1978; JaCOBY, 1991).

Para cada uno de los gráficos espaciales se utiliza una matriz de similitudes referente a una serie de proposiciones o acciones. Cada celda de la matriz es una medida de similitud y diferencia entre la organización de la columna y la organización de la fila. MDS toma dicha matriz y la convierte en un sistema euclidiano de distancias que más tarde se representa gráficamente. En la configuración espacial del gráfico cada organización viene definida en relación con las otras, pero su posición queda también definida por su relación con respecto al sistema de relaciones entre las otras organizaciones. Cada punto es una medida de una organización con referencia a las otras, más su posición en la red de relaciones de cada una de las otras organizaciones entre sí. La proximidad (o distancia) espacial entre dos (o más) organizaciones es el producto de su similitud y de su equivalencia en la forma en que se relacionan con otras organizaciones.

En nuestro análisis utilizamos dos tipos de matrices. Para analizar las similitudes ideológicas y políticas utilizamos matrices de proximidad simétricas. El valor de proximidad entre A y $B$ es igual al valor de proximidad entre B y A. Cada celda, de este grupo de matrices, representa la similitud entre las organizaciones de las filas y las de las columnas con respecto a temas políticos. Cada celda indica el número de temáticas políticas en las cuales las organizaciones de las filas y de las columnas coinciden. Los resultados reflejan la similitud y distancia entre organizaciones en sus posiciones ideológicas y políticas.

Para analizar las similitudes en la acción política se utilizan matrices asimétricas de proximidad. No se miden distancias (relaciones) simétricas sino más bien asimétricas. En este caso, una celda de la matriz indicando contacto político entre A y B no tiene necesariamente el mismo valor que la celda indicando contacto entre B y A. Las matrices asimétricas están basadas en las respuestas de los líderes de las organizaciones y reproducen la estructura jerárquica y de poder que domina las relaciones entre las organizaciones. Dado que se estudian la centralidad y la relación estructural entre organizaciones, se divide la OMC (Consejo General de Colegios Médicos) entre su estructura central (OMC) y los Colegios Provinciales (CPOM). Las celdas de las matrices contienen información acerca del nivel de acuerdo con la actividad política de cada una de las otras organizaciones, el tener ejecutivos comunes, tener el contacto político más fuerte y construir coaliciones para desarrollar actividades políticas. Este tipo de matrices y su tratamiento por MDS ofrecen como resultado gráficos de coaliciones políticas y mapas de poder. Los gráficos representan el paso de la identificación política entre las organizaciones hacia la colaboración política. Son una importante contribución al entendimiento de la acción colectiva (D. KNOKE, 1990 ; LAUMAN y KNOKE, 1987). 
Al analizar estos gráficos debemos fijarnos en dos aspectos complementarios: proximidad y distancia entre organizaciones y su distribución en la representación gráfica. La primera nos ofrece información acerca de la similitud y/o diferencia entre organizaciones y la formación de clusters. En la segunda (al ofrecernos el mapa geográfico de similitudes entre todos) podemos observar la influencia de diversas temáticas dividiendo al colectivo. Al final tenemos una imagen no únicamente de similitud entre organizaciones sino también de las razones/temáticas principales dividiendo el campo.

Las unidades básicas de cualquier sistema político complejo no son individuos sino posiciones o roles ocupados por actores sociales y las relaciones o conexiones entre ellos. Las redes sociales resultantes se convierten en fundamentales como mecanismos de creación de identidad colectiva y cohesión social, como elemento fundamental en la creación de sistemas de confianza y, por tanto, en la reducción de los costes de transacción, como vía fundamental en la resolución de conflictos, y como vehiculador principal de la acción colectiva (H. WHITE, 1992; E. Laumann y F. Pappi, 1976; D. KNoke, 1990). Para su estudio la aproximación más adecuada es el análisis de redes.

El análisis de rédes es una nueva aproximación teórica y metodológica que plantea explicar el comportamiento de los actores como resultado de su participación en relaciones sociales estructuradas (WeLLAN, 1988). El análisis de redes presupone que cualquier actor participa en un sistema social con muchos otros actores que se convierten en sus puntos de referencia. La naturaleza de las relaciones de cualquier actor con otros miembros del sistema puede afectar su percepción, creencias y acciones. Los procesos sociales y el comportamiento social deben ser explicados en relación a la red de relaciones que conectan a los actores. Esas relaciones sociales son independientes de los actores, de sus valores o creencias, y juegan el papel principal de distribuir de forma diferencial recursos escasos (información, recursos económicos, poder, etc.) (Wellman, 1983).

Pero el análisis de redes va más allá al considerar la estructura de relaciones entre actores y el posicionamiento del actor en la red como características con consecuencias importantes para el comportamiento, percepción y actitud de las unidades individuales y el sistema en su conjunto (KNOKE y KUKLINSKI, 1982). Las pautas relacionales de actores sociales en un sistema incorporan a su vez dimensiones limitantes y potenciadoras de la acción social. El análisis de redes intenta explicar el comportamiento de elementos de la red y del sistema en su conjunto recurriendo a las características de las interacciones entre elementos, buscando esas dimensiones limitantes y potenciadoras (RODRIGUEZ, 1995).

Para nuestro análisis hemos utilizado los programas específicos UCINET y KRAKPLOT. Los datos utilizados proceden de mi
Encuesta a la élite política sanitaria (1990) a una muestra de 166 altos cargos de organizaciones e instituciones médico-sanitarias y que da forma a mi trabajo The Politics of Medicine in Spain (1991).

\section{El espacio ideológico de la élite política}

La definición del modelo de organización de la sanidad no es un proceso concluido con la Ley General de Sanidad (1986). De hecho, y a pesar de que con la Ley General de Sanidad se articula el Sistema Nacional de Salud y parece sentenciarse una organización sanitaria con dominio público, desde entonces el proceso político (y debate) sobre las características de la sanidad ha seguido abierto. El debate sobre el modelo sanitario y el papel del Estado ha concentrado alguna de las disputas más acaloradas de los últimos años. Es sin duda el tema central de la política sanitaria de la década de los 80 y de la década de los 90. De la articulación de un modelo u otro dependen multiplicidad de intereses y proyectos: proyectos e intereses profesionales, de uso y distribución de recursos, de obtención de beneficios, de justicia social, de éficiencia clínica, etc.

El Gráfico 1 es una representación en dos dimensiones de la élite política médica sanitaria (agrupada en organizaciones) en relación a sus preferencias con respecto a la organización del sistema sanitario. Las temáticas incluidas son: preferencia por un dominio privado o público del sistema sanitario; extensión de las prestaciones del sistema sanitario público (universal o restringida); pago por servicios públicos (libre o con alguna contribución por parte del paciente); y provisión de servicios sanitarios públicos (exclusivamente por instituciones públicas o con la colaboración de instituciones privadas).

El Gráfico nos ofrece visualmente dos tipos de información. En primer lugar, visualizamos la proximidad de las organizaciones en tres clusters principales, con un alto nivel de similitud entre las posiciones de las organizaciones que forman los clusters: OMC y CESM; sindicatos tradicionales (CCOO y UGT), FADSP y partidos de izquierda; partidos de derecha, Administración, líderes y expertos. La posición de los clusters en el gráfico también nos indica la división espacial de las organizaciones de acuerdo con dos dimensiones: 1.- preferencia por dominio público o privado del sistema sanitario (dimensión diagonal); y 2.extensión del sistema público o extensión del sistema privado dentro del Sistema Nacional de Salud (diagonal horizontal). El cluster formado por OMC/CESM defiende un sistema no monopolizado por el sistema público y aboga por el incremento del papel del sistema privado dentro del SNS. El cluster forma- 


\section{ACUERDO CON EL MODELO SANITARIO}

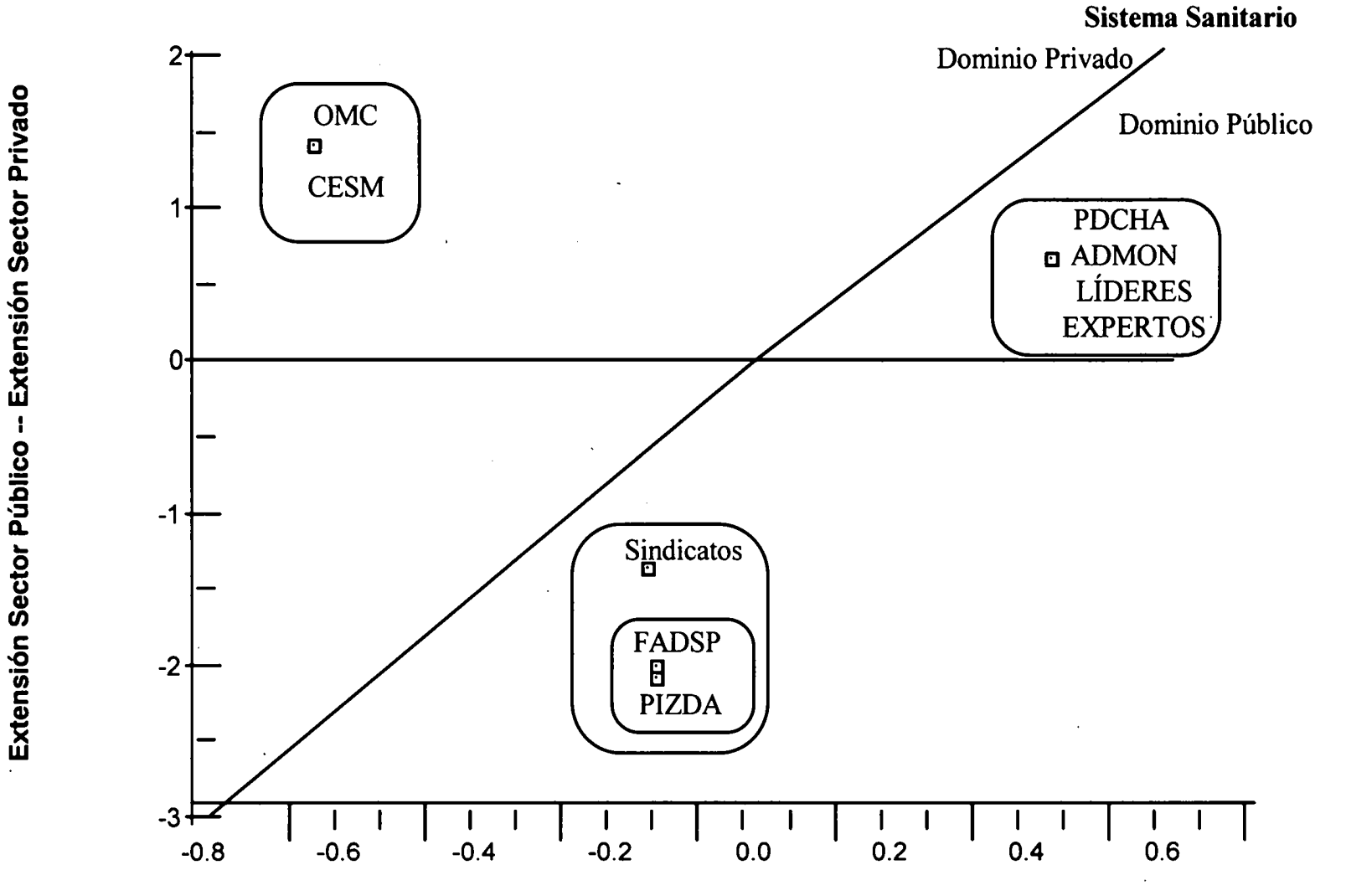

$\mathrm{RSQ}=.983$

KRUSKAL'S STRESS $=.083$

OMC = Organización Médica Colegial-Consejo General de Colegios Oficiales de Médicos; CESM= Confederación Española de Sindicatos Médicos; FADSP= Federación de Asociaciones para la Defensa de la Sanidad Pública; Sindicatos= Comisiones Obreras y UGT; PIZDA= Líderes de Partidos de Izquierdas; PDCHA= Lideres de Partidos Conservadores; ADMON= Aitos cargos de la Administración del Estado (a nivel central y autonómico); LíDERES: Líderes de pequeñas organizaciones profesionales y sectoriales; EXPERTOS: Expertos sanitarios.

do por partidos de derecha/Administración/líderes/expertos defiende un sistema dominado por el sector público pero defiende también el incremento del rol del sector privado dentro del SNS. El cluster más radical y de izquierda (sindicatos tradicionales, FADSP y partidos de izquierda) defiende el dominio público en sanidad y propone la monopolización pública del SNS y la reducción drástica del sector privado. El Gráfico 1 es una perfecta representación de los tres principales planteamientos implicados en la reforma del sistema sanitario. La distancia (oposición) entre cada uno de los cluster es similar.

El Gráfico 2 representa las posiciones de los principales grupos sanitarios con respecto al papel social redistributivo del sistema sanitario público (SNS). La matriz de proximidades incluye la similitud/diferencia entre actores políticos en relación a: la importancia dada a la reducción en el acceso, atención y desigualdades sanitarias en general en la política sanitaria futura; acentuar el papel redistributivo del SNS como su mejor cuali- dad; y acentuar la orientación colectiva redistributiva como la mejor razón para defender al sector público. La FADSP, los sindicatos tradicionales y los líderes forman un cluster muy compacto con las posiciones más radicales apoyando la orientación colectiva y de redistribución social del sistema sanitario. La CESM y los partidos políticos (conservadores y de izquierdas) forman un cluster menos compacto que está de acuerdo principalmente con el papel positivo del sistema sanitario público sobrepasando las desigualdades socio-ecnómicas. La OMC se distingue por su total desinterés con respecto de la temática redistributiva. La dimensión horizontal corta la representación gráfica en dos conceptos principales: por debajo del eje están situados aquellos actores políticos que apoyan fuertemente una mayor igualdad y la reducción de desigualdades sanitarias en la política sanitaria futura más aquellos que acentúan el papel redistributivo del sistema sanitario público. Por encima del eje horizontal la preocu- 
pación por las desigualdades sociales como el elemento central en la futura política sanitaria es mucho menor. El cluster formado por CESM y los partidos políticos no considera tampoco que el aspecto más destacable del sistema sanitario sea su papel redistributivo, pero coinciden en apoyar al sector público por sobrepasar las desigualdades socio-económicas. En la esquina superior izquierda encontramos a la OMC, que no apoya el sistema público ni su papel redistributivo.

\section{Grifico 2}

\section{Representación de Similitudes MDS}

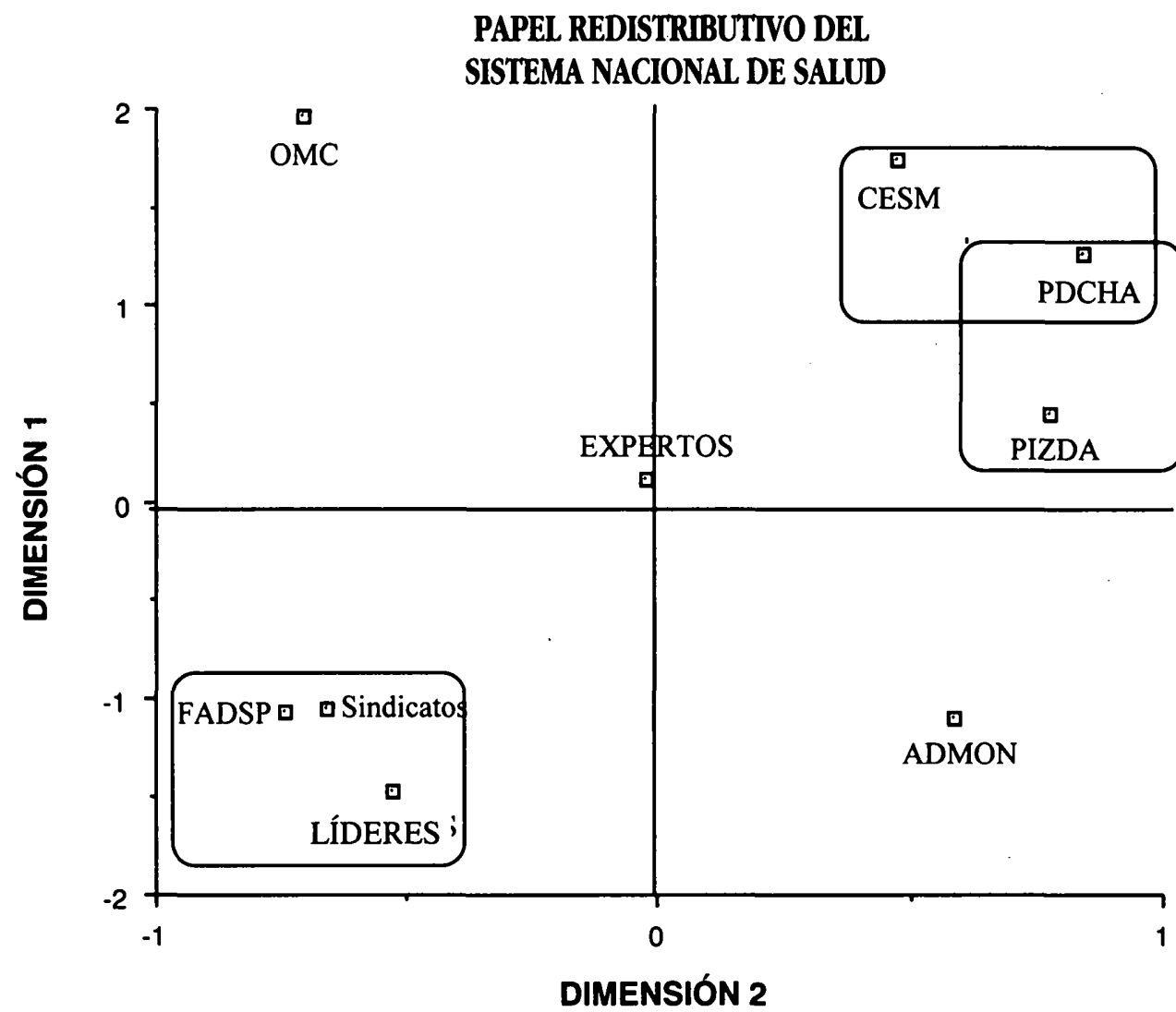

DIMENSION 1- Reducción de desigualdades de salud en la política sanitaria futura DIMENSION 2a Posiciones ideológicas us. pragmáticas

$\mathrm{RSQ}=.866$

K'S STRESSa .164

LA OMC está situada en una posición totalmente opuesta a la FADSP, los sindicatos tradicionales y los líderes de las pequeñas asociaciones profesionales. Mientras que CESM/partidos de derecha/partidos de izquierda y Administración están situados en una situación intermedia: resaltan el rol redistributivo del SNS pero no son las proponentes más fuertes de que la reducción de las desigualdades deba guiar la política sanitaria. La dimensión vertical parece dividir a los grupos en dos conjuntos. Uno claramente ideológico: OMC contra el sector público y FADSP/sindicatos tradicionales/líderes de pequeñas asociaciones profesionales a favor del sistema público y de su papel redistributivo. El otro es un conjunto más técnico y administrativo, más preocupado acerca del fun- cionamiento del sistema y resaltando mucho menos los aspectos ideológicos.

La matriz de proximidades que da lugar al Gráfico 3 incluye seis temáticas profesionales. Cada celda de la matriz representa el número de temáticas en que las organizaciones están de acuerdo. Las temáticas son: libertad de elección de médico; aumento o reducción del número de profesionales; afliación libre u obligatoria a los Colegios de Médicos; control profesional o estatal del número de profesionales y de la práctica profesional; y preferencia por la jurisdicción médica o la civil para juzgar los errores médicos.

Podemos ver tres claros clusters con niveles altos de similitud. CESM y OMC mantienen un alto nivel de acuerdo en casi 


\section{Gráfico 3}

Representación de Similitudes MDS

\section{ACUERDO CON RESPECTO A TEMAS PROFESIONALES}

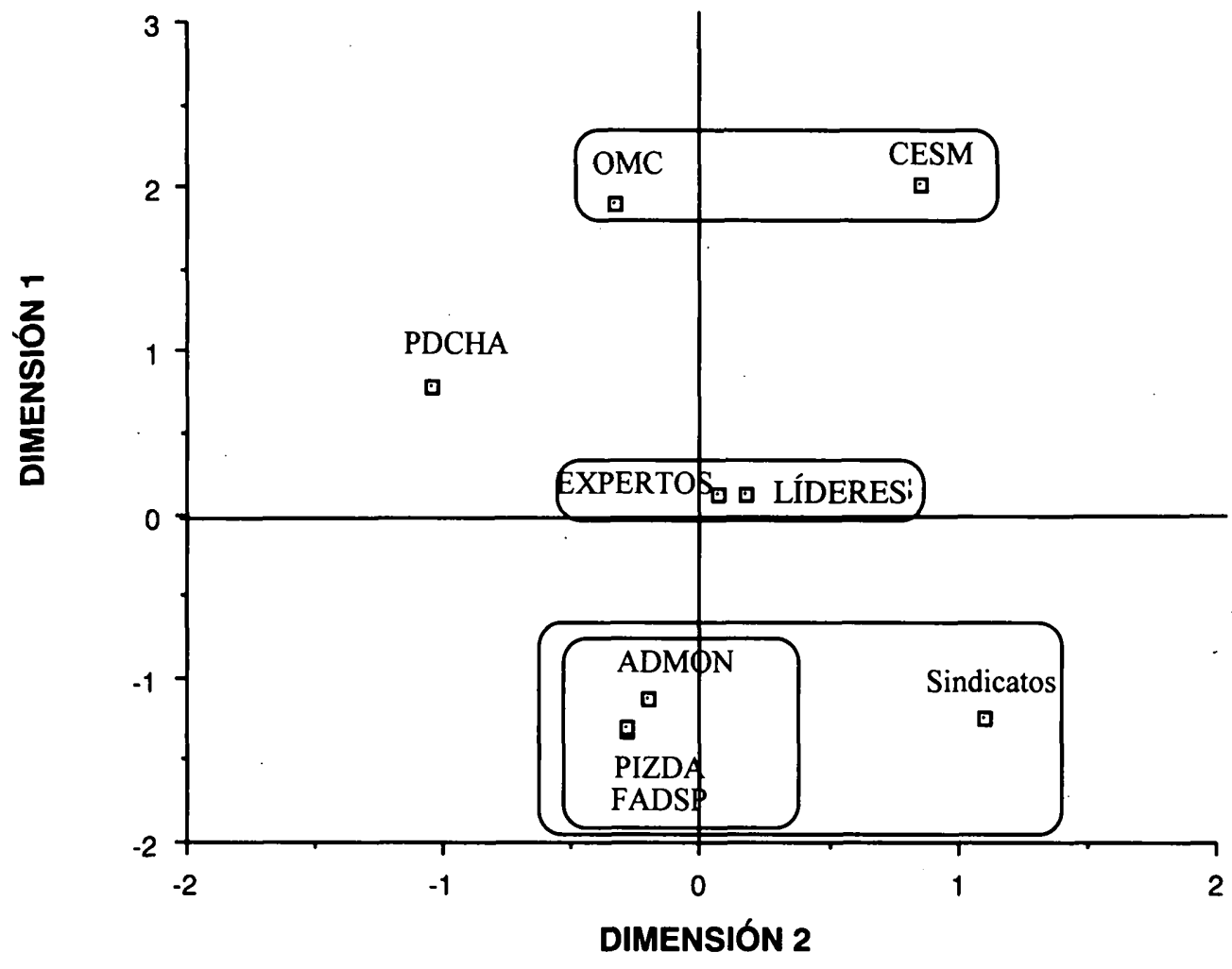

DIMENSIÓN 1 = Control sobre la profesión; Elección de médico.

DIMENSIÓN 2= Reducción $v$ s. incremento en el número de médicos

$\mathrm{RSQ}=.928$

K'S STRESS $=.124$

todos los aspectos: aumentar la libre elección del médico y evitar el control estatal de la profesión. Administración/FADSP/partidos de izquierdas/sindicatos tradicionales coinciden en no querer la libre elección del médico y abogan por un alto nivel de control estatal sobre la profesión y su práctica. El grupo intermedio de expertos/líderes está situado en una posición ideológica también intermedia: defiende la libre elección del médico pero en cambio se decanta por un mayor control del Estado sobre la profesión, aunque no tan radicalmente como el cluster de izquierdas. El Gráfico se divide horizontalmente entre posiciones totalmente liberalizantes de la profesión y control sobre la profesión. La dimensión (eje) vertical corta el espacio de las organizaciones médicas entre aquellas que abogan por la reducción del número de profesionales (izquierdas) y aquellas que abogan por mantener o incrementar su número (derecha). CESM y sindicatos tradicionales están opuestos ideológicamente y también en posiciones diametralmente opuestas en el mayor corte ideológico (libertad-control de la profesión). Coinciden sin embargo en la necesidad de un mayor número de profesionales. La temática que divide de forma principal al colectivo es acerca del control/no control de la profesión y su práctica profesional. La derecha profesional (OMC/CESM) está situada en la posición totalmente opuesta a la izquierda sanitaria y profesional. Esa dimensión es la que domina la concepción ideológica sobre la profesión y la que cataliza la similitud/diferenciación ideológica entre las organizaciones.

El Gráfico 4 de similitudes es el resultado de utilizar MDS con la matriz de proximidades de las organizaciones con respecto a seis temáticas estrechamente relacionados con (y que definen) el status profesional de los médicos. Cada celda es el número de posiciones similares entre organizaciones con respecto a: acuerdo o desacuerdo con los tres procesos de reforma que afectan la práctica de los profesionales en el sistema sanitario (Estatuto Marco, Sistema de retribuciones y Jornadas laborales); dedicación exclusiva como empleado del sector público; 


\section{Girifico 4}

\section{Representación de Similitudes MDS}

\section{ACUERDO CON RESPECTO STATUS PROFESIONAL}

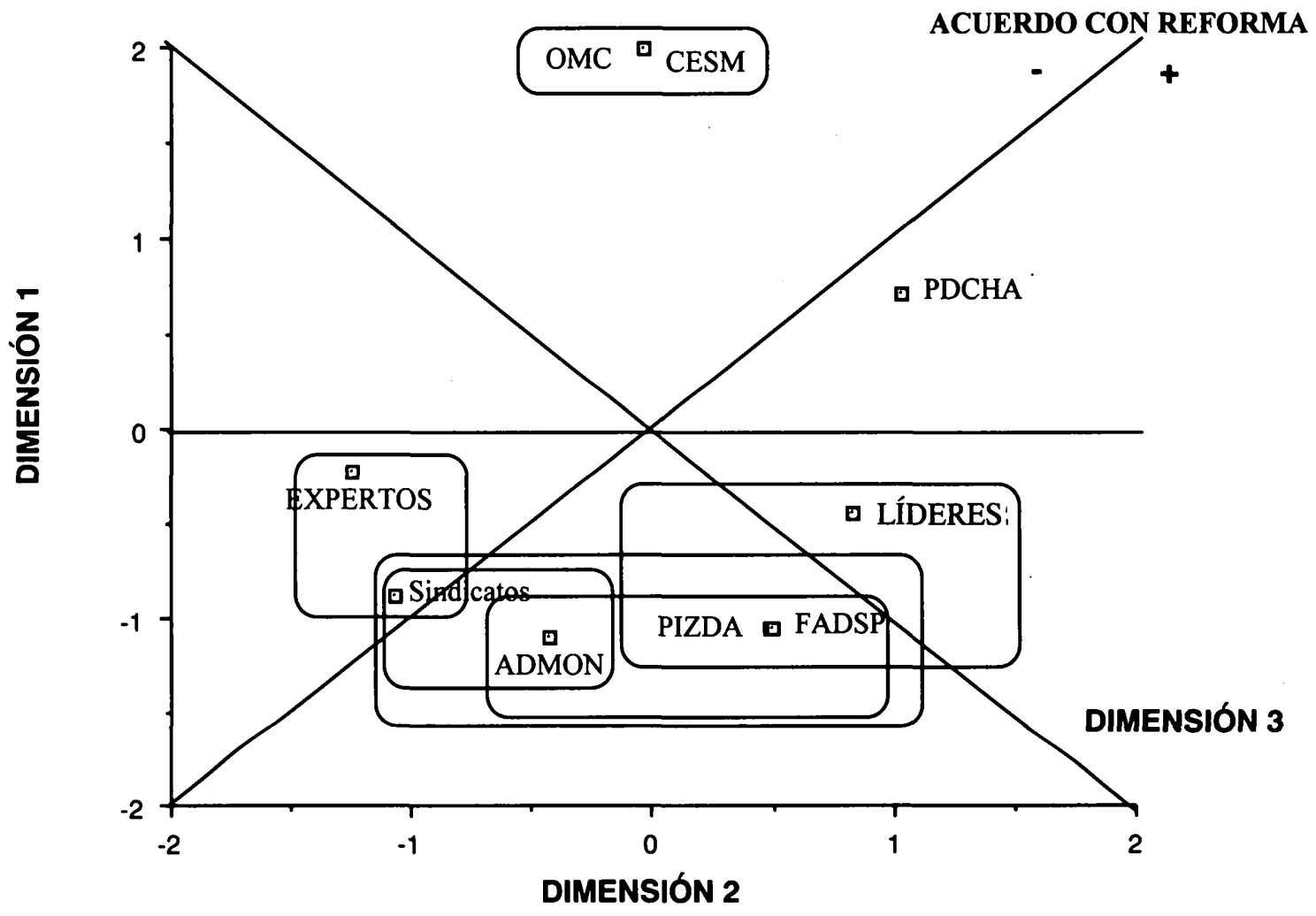

DIMENSION 10 status de empleado con dedicación exclusiva us. status profesional sin dedicación exclusiva

DIMENSIÓN 30 Directores de centros sanitarios: médicos us. especialistas en gestión.

RSQ- .949

K'S STRESS= 100

status profesional us. laboral; y preferencia por profesionales o especialistas en gestión como directores de las instituciones sanitarias. El campo ideológico profesional está claramente dividido por el eje horizontal con respecto al status profesional: en la parte superior se sitúan OMC/CESM/partidos de derecha que defienden un status de tipo profesional y están en contra de la dedicación exclusiva (defensa de un tipo liberal de profesión). En la parte inferior se sitúan el resto de los grupos, que definen a la profesión como empleada en grandes organizaciones públicas. La diferenciación entre la percepción liberal y la percepción como empleada de la profesión es la temática que con mayor intensidad divide al colectivo político. Los dos ejes diagonales dividen también al colectivo launque con menos intensidad]. El eje ascendente divide el Gráfico entre aquellos que están en desacuerdo con los aspectos profesionales (Estatuto Marco, Retribuciones, Jornada laboral) de la reforma versus los que los apoyan. El eje descendente divide el Gráfico entre los que defienden la posición de que los directivos sean médi- cos frente a los que quieren que sean especialistas en gestión. Los clusters más compactos ideológicamente son los que están en posiciones totalmente opuestas. Están formados por OMC/CESM len desacuerdo con la reforma, status profesional, contra dedicación exclusival frente a la Administración/partidos de izquierdas/FADSP [de acuerdo con la reforma, status de empleado, a favor dedicación exclusiva, y en contra de los médicos como directivos]. En el área de influencia del cluster conservador tenemos a los partidos de derechas que si bien apoyan el status profesional están en desacuerdo con OMC/CESM con respecto al tipo de directivos para las instituciones sanitarias. Todos los demás grupos de actores giran alrededor del cluster central de la izquierda y de la propuesta más radical de proletarización del status profesional (Administración/partidos de izquierda/FADSP). Los líderes de pequeñas organizaciones profesionales están en desacuerdo con este cluster en el tipo de directivos para los centros; y los sindicatos tradicionales y expertos con respecto a la reforma. Mientras que expertos y líde- 
res están situados en los límites exteriores de la dimensión, los sindicatos están muy próximos ideológicamente al cluster central. A pesar de la diferenciación, el eje horizontal (la dimensión profesional $v s$. empleado) es el que divide y aglutina ideológicamente con más intensidad [de forma muy dominante] a los actores de la política sanitaria.

El Gráfico 5 es la representación gráfica de las similitudes y distancias entre organizaciones en el acuerdo o desacuerdo con respecto a la reforma sanitaria socialista y la forma en que ha sido aplicada. La matriz de proximidades contiene similitudes en doce temáticas: acuerdo con el contenido y la aplicación de la Ley General de Sanidad y la Ley de Incompatibilidades; acuerdo con los objetivos y la aplicación de la reforma en su conjunto y las reformas hospitalaria y de atención primaria; éxito o fracaso global de la reforma; y necesidad por un cambio radical en la orientación de la reforma frente a la idea de mantener los mismos objetivos. El eje diagonal ascendente divide el Gráfico entre aquellas organizaciones que están en contra de la reforma y su aplicación y que consideran han sido un fracaso y aquellos que la apoyan y consideran que ha sido un éxito. Cada una de las dos partes está dominada por un cluster central (en total oposición al contrario). OMC/CESM/Partidos de derecha destacan por su alta homogeneidad contra la reforma, que consideran ha fracasado y que debe ser reemplazada por una totalmente nueva. FADSP/partidos de izquierdas/Administración mantienen un alto nivel de homogeneidad en su apoyo a la reforma, considerando que relativamente ha sido un éxito, y defendiendo cambios muy pequeños. Gráficamente, los dos cluster están totalmente opuestos. Los sindicatos tradicionales están en una situación intermedia: bastante en contra de la reforma y su aplicación, que piensan ha fracasado, pero en cambio no defienden cambios radicales en la reforma. Tanto los líderes como los expertos oscilan alrededor del cluster que apoya la reforma socialista (aunque con algo menos de intensidad). El eje dominante de división de la élite político médica es el acuerdo/desacuerdo (y percepción de éxito/fracaso) con la reforma. La necesidad de una nueva reforma aglutina fuertemente al cluster conservador y distancia a los sindicatos de las organizaciones conservadoras y hacia las organizaciones que apoyan la reforma.

Griajico 5

Representación de Similitudes MDS

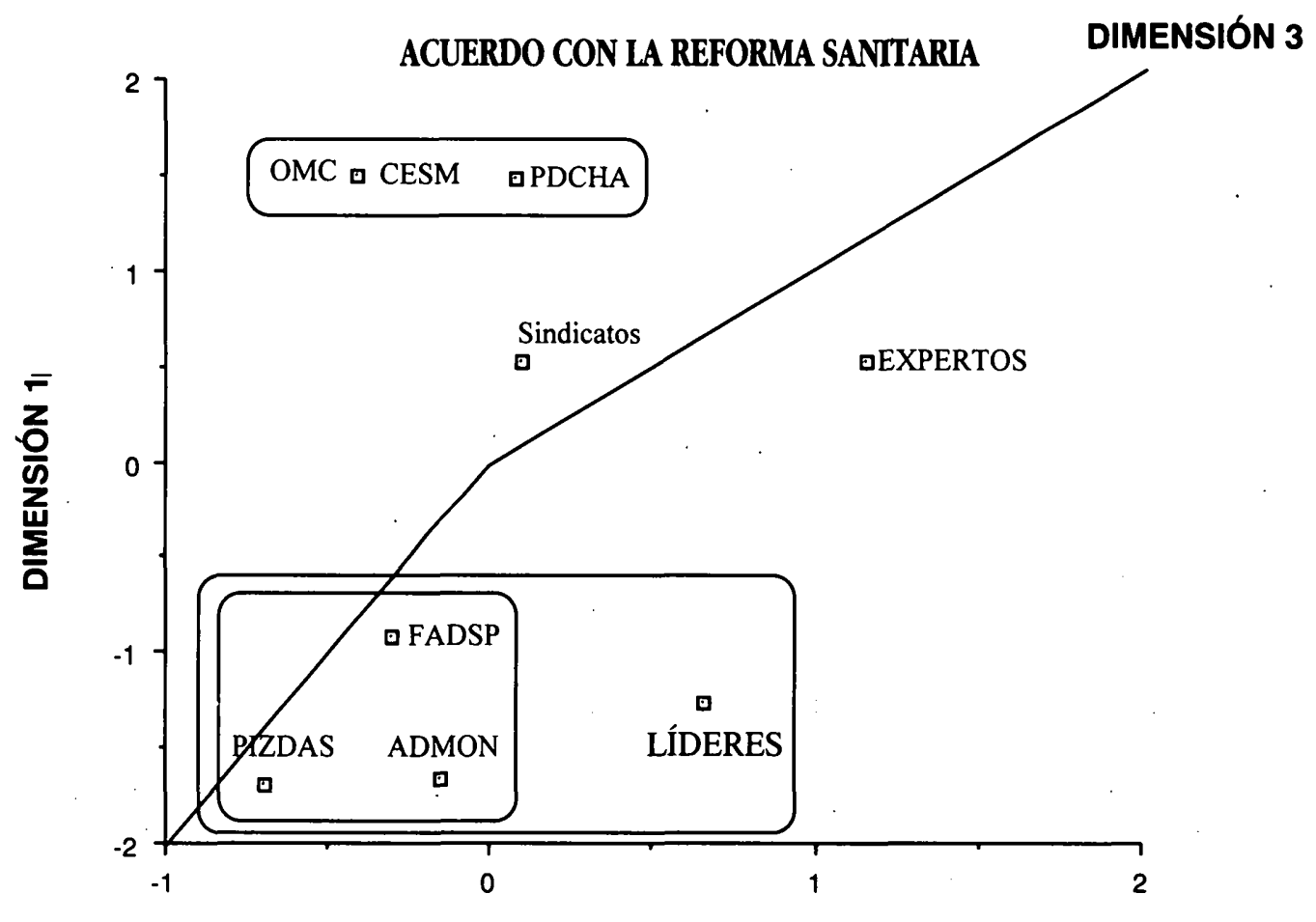

DIMENSIÓN 2

DIMENSION $3=$ Desacuerdo y fracaso de la reforma sanitaria $u s$. acuerdo y éxito de la reforma 


\section{CONFIANZA EN EL SISTEMA POLÍTICO}

\section{CONFIANZA EN ESTADO}

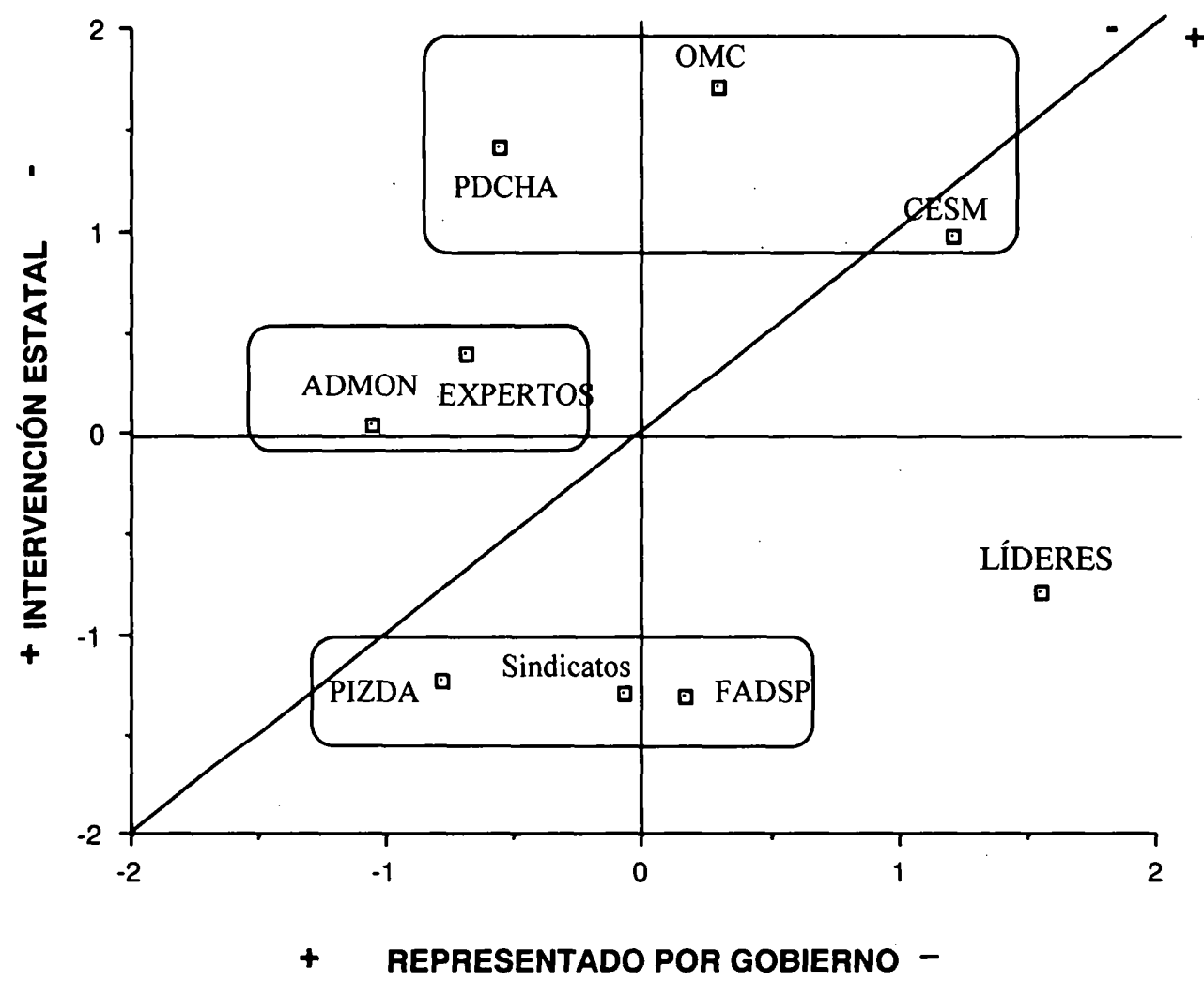

RSQ- .894

KRUSKAL'S STRESS- .121

El Gráfico 6 representa la confianza global en el sistema político y el Estado. La matriz de proximidades está compuesta del número de similitudes entre las organizaciones con respecto a: sentirse representado por el gobierno, partido que mejor la representa; necesidad de mayor o menor intervencionismo estatal; y capacidad del Estado para resolver problemas. En términos de identificación política, la élite se divide en tres grupos, uno en la derecha política [OMC/CESM/partidos de derecha] y dos en la izquierda política [expertos/Administración] [partidos de izquier$\mathrm{da} /$ sindicatos tradicionales/FADSP]. De nuevo existe una clara oposición entre los clusters ideológicos conservador y el más radical. El cluster formado por Administración/expertos es de tipo más pragmático y se mantiene en una posición intermedia entre las dos. Tres temáticas dividen el campo político siguiendo tres ejes. El eje vertical divide el campo entre los que se sienten representados por el gobierno y los que no. El eje horizontal divide el espacio entre los que apoyan un mayor intervencionismo del Estado y los que quieren reducirlo. Y el eje ascendente parte el espacio entre los que confían en la capaci- dad del Estado y los que no. Curiosamente, los clusters que están determinados por su nivel de proximidad y similitud con respecto a ellos mismo y con respecto al resto de las organizaciones están a su vez divididos por las diversas dimensiones. El cluster más compacto es el más pragmático [Administración/expertos] que no confía mucho en la capacidad del Estado y que (a pesar de estar en la izquierda) aboga por reducir el intervencionismo del Estado, y en general se siente representado por el gobierno. El cluster conservador (ideológicamente normalmente muy compacto) se divide entre los que confían en el gobierno y los que no (OMC/CESM). Mientras que OMC/CESM no se sienten representados por ningún gobierno, los partidos de derechas están próximos a los gobiernos autonómicos. El cluster está fuertemente unido por su oposición a la intervención del Estado. En la posición totalmente opuesta, el cluster más radical apoya un mayor intervencionismo del Estado. Internamente está dividido entre los partidos de izquierdas y sindicatos más próximos al gobierno y FADSP que se siente muy lejano del gobierno. Cercanos al cluster (y especialmente a FADSP) los líderes 
de las pequeñas organizaciones profesionales están a favor de un mayor intervencionismo estatal pero no confian en el gobierno. La dimensión más importante que divide las posiciones de la élite política es el deseo de un mayor o menor intervencionismo. Radicaliza los patrones de los dos grandes clusters y sitúa a los otros actores políticos en posiciones intermedias. No sólo es la dimensión estadísticamente más importante sino también la más relevante políticamente y la que en mayor grado determina acciones y programas políticos de un tipo u otro.

El Gráfico 7 es el resultado de la utilización de MDS con todas las matrices ideológicas a la misma vez. Representa gráficamente la similitud entre las organizaciones con respecto a la totalidad de la ideología política. Existen cuatro claros cluster muy homogéneos internamente y que a su vez reflejan la división del campo político en la dimensión horizontal y la vertical. La dimensión vertical es la dimensión política izquierda-derecha y la dimensión horizontal divide el espacio político entre intereses profesionales e intereses sanitarios. En la derecha política tenemos al cluster profesional CESM/OMC con una ideología sanitaria prácticamente igual (y en la cual la defensa de la profesión es el aspecto dominante) y a cierta distancia al cluster partidos de derechas/expertos que representa intereses sanitarios no únicamente profesionales. En la izquierda tenemos a la izquierda profesional (sindicatos tradicionales/FADSP) totalmente opuesta a los planteamientos de CESM/OMC, pero que está centrada en la defensa de los intereses profesionales, y a cierta distancia pero con planteamientos sanitarios (y no profesionales) a la Administración y los partidos de izquierda. Los líderes -individuales están en la órbita del cluster profesional radical. El campo de la política sanitaria, aparte de estar dividido entre posiciones conservadoras (que apoyan la libertad profesional, el sector privado y la no intervención del Estado) y las posiciones de izquierdas (que apoyan el dominio público de la sanidad, el mayor intervencionismo del Estado, y la reducción de la profesión a status de empleada), está también dividido ideológicamente por el dominio de intereses profesionales e intereses

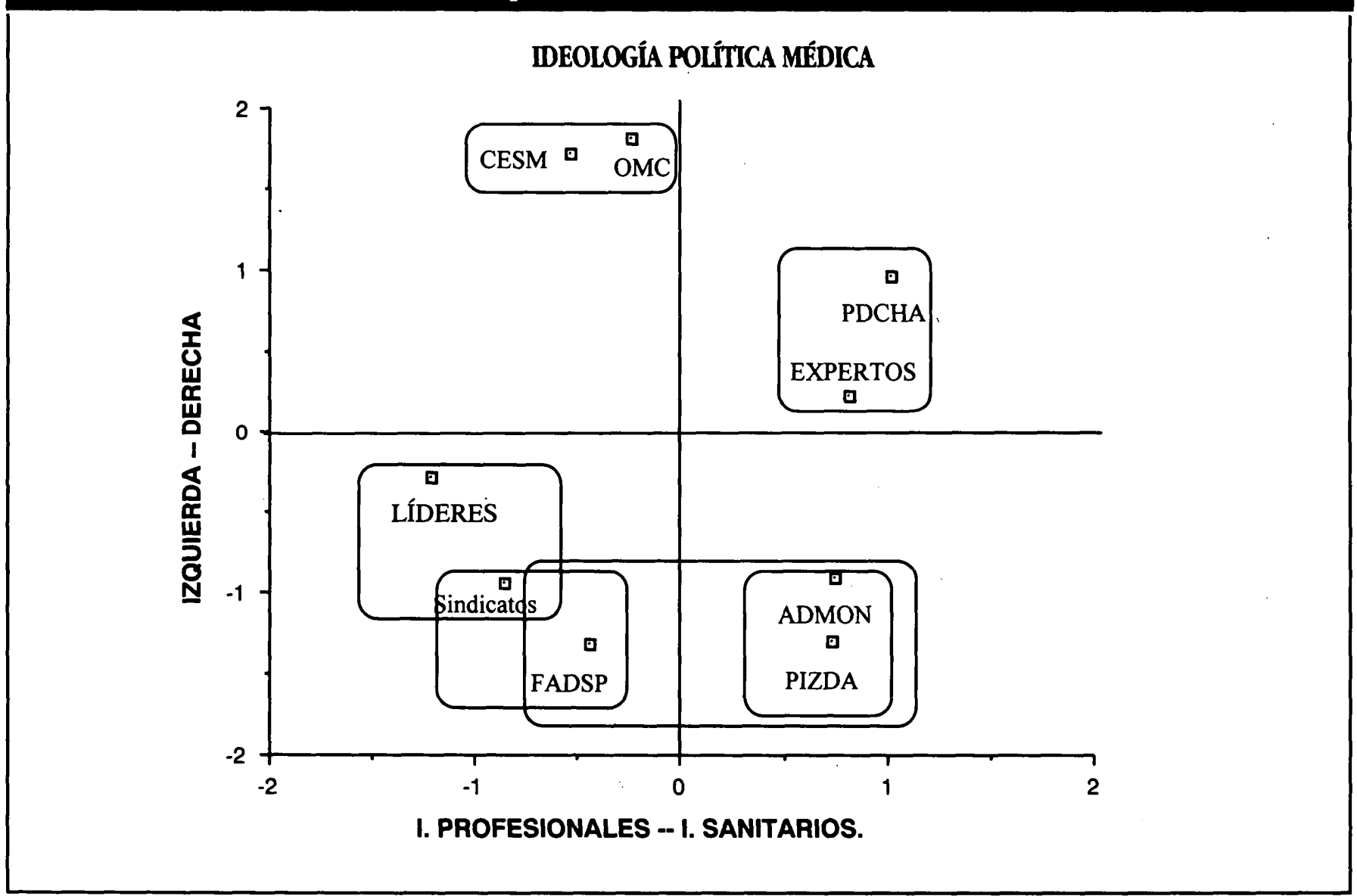


globales del sistema sanitario. En el lado izquierdo del Gráfico encontramos a las organizaciones profesionales altamente ideológicas y políticas, y en el lado derecho tenemos organizaciones e intereses políticos preocupados con la organización y funcionamiento del sistema sanitario en su conjunto.

\section{El campo de actividad política}

Un paso hacia adelante en la comprensión de las organizaciones de intereses y el campo de la política sanitaria consiste en analizar en profundidad la acción colectiva. Un sistema es utilizar técnicas de Escalado Multidimensional (normalmente conocidas como MDS) para analizar la actuación de las organizaciones de interés, sus relaciones y la formación de alianzas y coaliciones. El objetivo es construir un mapa de las similitudes en la acción política que permita entender la dinámica de la política sanitaria española en su totalidad. Se trata de determinar la estructura de los actores y las organizaciones en el campo sanitario, en base a sus percepiones acerca de los otros y en sus pautas de interacción.

Para analizar las similitudes en la acción política se utilizan matrices asimétricas de proximidad. No se miden distancias (relaciones) simétricas sino más bien asimétricas. En este caso una celda de la matriz indicando contacto político entre A y B no tiene necesariamente el mismo valor que la celda indicando contacto entre B y A. Las matrices asimétricas están basadas en las respuestas de los líderes de las organizaciones y reproducen la estructura jerárquica y de poder que domina las relaciones entre las organizaciones. Dado que se estudian la centralidad y la relación estructural entre organizaciones, se divide la OMC (Consejo General de Colegios Médicos) entre su estructura central (OMC) y los Colegios Provinciales (CPOM). Las celdas de las matrices contienen información acerca del nivel de acuerdo con la actividad política de cada una de las otras organizaciones, el tener ejecutivos comunes, tener el contacto político más fuerte y construir coaliciones para desarrollar actividades políticas. Este tipo de matrices y su tratamiento por MDS ofrecen como resultado gráficos de coaliciones políticas y mapas de poder. Los gráficos representan el paso de la identificación política entre las organizaciones hacia la colaboración política. Son una importante contribución al entendimiento de la acción colectiva (D. KNOKE, 1990; LAUMAN y KNOKE, 1987).

El Gráfico 8 es la representación en dos dimensiones de la matriz de similitudes de cada organización con respecto al acuerdo con relación a la actuación y política de las organizaciones que forman el campo sanitario. Existen dos grandes agrupamientos (clusters), uno en la izquierda y otro en la derecha política. En la zona de la derecha política (por encima del eje horizontal) el núcleo central del cluster conservador está formado por OMC, con CESM y los Colegios Provinciales (muy próximos entre ellos) a cierta distancia. La distancia con respecto a OMC se debe a la relación asimétrica con respecto a OMC: dado que tanto CESM como CPOM están más de acuerdo con OMC que al revés. Las asociaciones de centros sanitarios privados (OCSP) están próximos al cluster conservador aunque no forman parte del mismo. El cluster de la izquierda está formado por FADSP y los sindicatos tradicionales (Comisiones Obreras y UGT) con una alta homogeneidad política e ideológica que se traduce en mutuo acuerdo. Están en una posición diametralmente opuesta al cluster conservador, reflejando el alto grado de desacuerdo y confrontación entre los dos clusters. Las pequeñas asociaciones profesionales sectoriales (APS) están más próximas a la izquierda profesional que a la derecha profesional. Están algo más de acuerdo con la actuación de la izquierda profesional que con la actuación de la derecha profesional.

El Gráfico 9 es una representación gráfica en dos dimensiones del nivel de desacuerdo con la actuación política de las otras organizaciones. Nos ofrece información acerca de los principales antagonismos entre organizaciones, dado que aquí la cercanía espacial refleja desacuerdo. La oposición entre las organizaciones de derechas y de izquierdas se polariza: CESM frente a OCSP, y FADSP frente a CPOM. La oposición entre los sindicatos tradicionales y las asociaciones profesionales sectoriales (APS) radica en la diferencia en sus planteamientos: sindical en un caso y profesional en el otro, a pesar de que ideológica y políticamente no son grandes oponentes. La representación gráfica refleja la centralidad referencial de la OMC, tanto con respecto de sus aliados (CESM y Colegios Provinciales), que se sitúan en una posición opuesta, como con respecto de las otras organizaciones de intereses.

El Gráfico 10 es la representación gráfica de la matriz que contiene información acerca de los puestos ejecutivos compartidos en diversas organizaciones por los líderes de cada organización. El gráfico es similar a los anteriores. Existe un aito nivel de ejecutivos comunes entre FADSP y los sindicatos tradicionales (CCOO y UGT) y también entre los Colegios Provinciales (CPOM) y la CESM. La distancia entre OMC y CPOM-CESM refleja la asimetría en sus relaciones. Si bien los líderes de OMC tienen cargos en CPOM y CESM, la situación inversa no es equivalente. Esto confirma que OMC ocupa una posición central con respecto a las organizaciones profesionales conservadoras.

La centralidad de OMC y la asimetría de las relaciones entre las organizaciones queda reflejada en el Gráfico 11. La OMC es el centro del cluster formado por las organizaciones profesionales conservadoras en referencia a las organizaciones con las cuales establecen un mayor contacto. El contacto más alto se 
Representación de Similitudes MDS

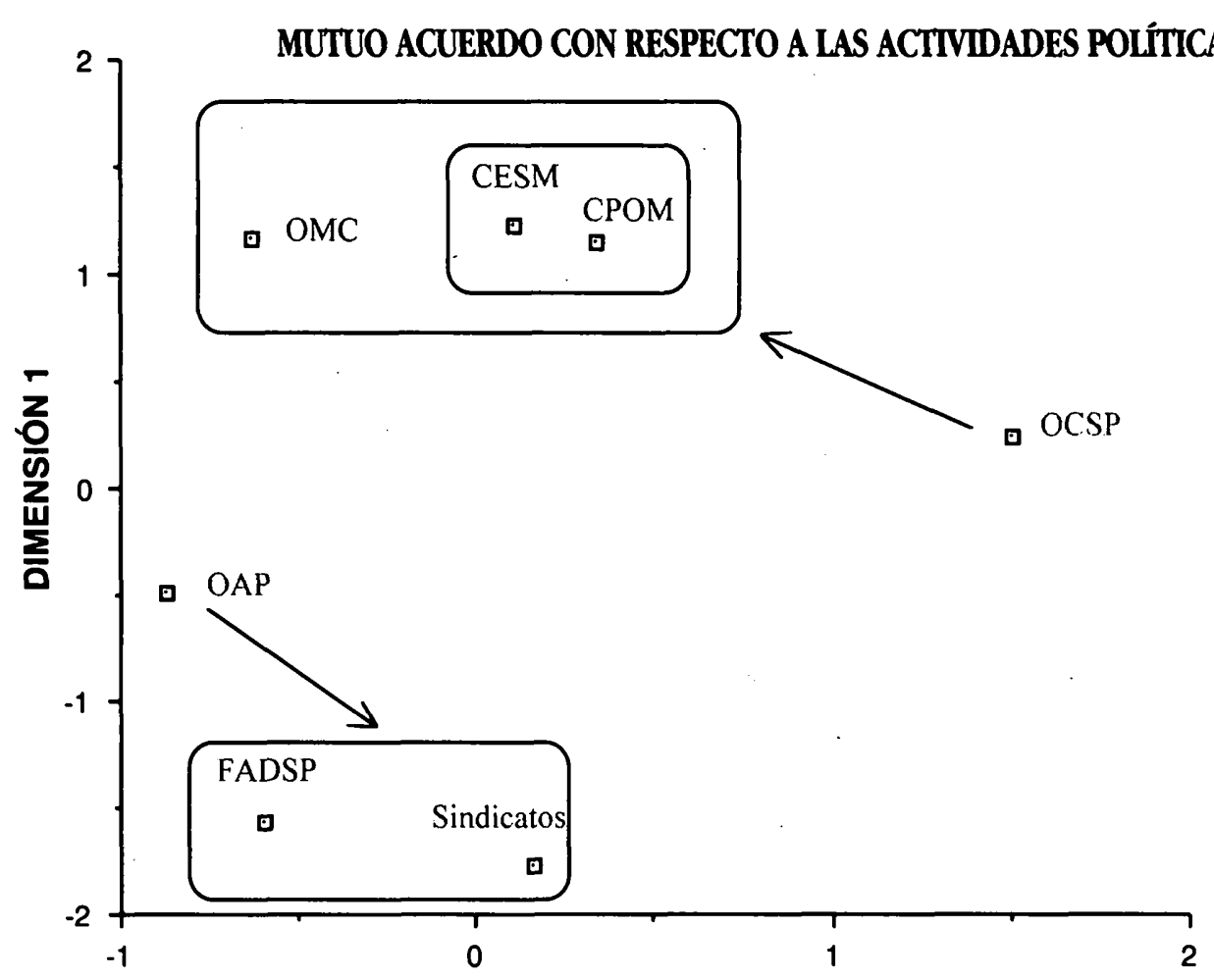

DIMENSIÓN 2

$\mathrm{RSQ}=.873$

KRUSKAL'S STRESS $=.191$

OMC = Organización Médica Colegial-Consejo General de Colegios Oficiales de Médicos

CESM= Confederación Española de Sindicatos Médicos

$\mathrm{CPOM}=$ Colegios Provinciales Oficiales de Médicos

FADSP= Federación de Asociaciones para la Defensa de la Sanidad Pública

Sindicatos= Federaciones de Sanidad de Comisiones Obrems y UGT

$O A P=$ Otras Asociaciones Profesionales

OCSP $=$ Organizaciones de Centros Sanitarios Privados

produce dentro de la propia organización profesional oficial, entre la estructura central y la periférica. CESM depende de ambas organizaciones, aunque especialmente de OMC. La oposición (no existencia de contactos) entre el cluster conservador y el radical se pone de evidencia en su posición opuesta en el gráfico.

El Gráfico 12 es la representación gráfica de la matriz de coaliciones entre las organizaciones. En la banda conservadora queda patente la centralidad de la OMC como líder de la acción colectiva. Los Colegios Provinciales y la CESM dependen para su acción políica de la OMC. Las asociaciones sectoriales de la profesión quedan también englobadas (aunque en el exterior) en el cluster de acción colectiva de las organizaciones profesionales conservadoras. Su acción políica es muy dependiente de
OMC y también de CPOM y CESM. La centrales sindicales Comisiones Obreras y UGT junto a FADSP forman una coalición muy estrecha en directa oposición política y de acción con la OMC y sus aliados. La acción política colectiva de las organizaciones profesionales está dividida en dos grupos: el dirigido por la OMC y la coalición (más compacta) entre centrales sindicales y FADSP.

El Gráfico 13 es la representación gráfica de todas las matrices de similitudes y distancias procesadas por MDS consideradas previamente. En términos de acción política, siguiendo las simetrías ideológicas, las organizaciones profesionales se agrupan en dos grandes coaliciones: la conservadora (OMC como líder, y Colegios Provinciales y CESM) y la radical (centrales sindicales, con el papel líder, y FADSP). Son dos clusters con 


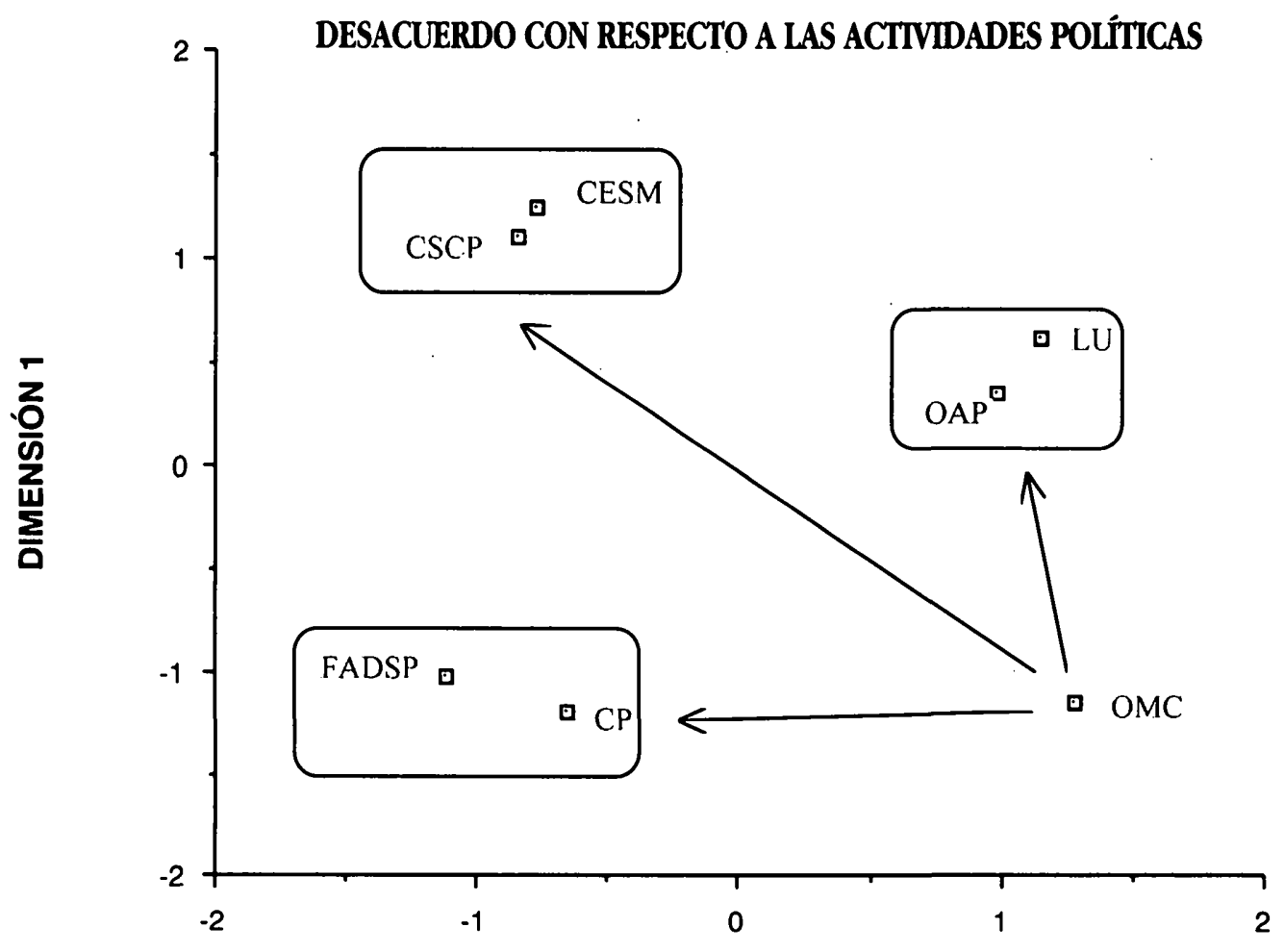

DIMENSIÓN 2

$\mathrm{RSQ}=.644$

KRUSKAL'S STRESS- .306

dos posiciones políticas bien diferenciadas y con dos tipos de acción política también diferenciadas. La proximidad entre las asociaciones de centros sanitarios privados (OCSP) y las asociaciones profesionales sectoriales (APS) no refleja su proximidad en acción sino la distancia (similar) con respecto a los dos grandes clusters.

La política profesional no sólo está dominada por la división entre planteamientos conservadores y radicales sino por la acción colectiva y no individual de las organizaciones. Esta serie de gráficos pone de manifiesto la estrecha colaboración y ligamen entre las organizaciones con proyectos políticos similares. Las organizaciones no actúan individualmente en el proceso político sino que forman grupos de actuación ideológicamente compactos. La dinámica de la política sanitaria y profesional genera varios grupos compactos de organizaciones. El campo de la política profesional está dividido entre un grupo conservador (con una representación política dominante y una representación sindical fuerte) y el grupo radical (también con una representación política y una representación sindical). Son dos coaliciones políticamente opuestas, con proyectos profesionales alternativos, que utilizan mecanismos políticos diferenciados. Luchan por dominar la representación política de la profesión y por conseguir que sus proyectos profesionales y sanitarios sean los dominantes en el colectivo y puedan ser aplicado con éxito. La coalición conservadora tiene un proyecto sanitario privatizante donde la profesión médica juega un papel central como profesión liberal. La coalición de izquierdas en cambio tiene un proyecto socializante-colectivista de la sanidad en el cual la profesión médica es vista de forma funcional como proveedora de fuerza de trabajo. Este conjunto de gráficos pone también de manifiesto la estructura de poder entre las organizaciones. La OMC se configura como la organización central en la dinámica ideológica y política de la coalición conservadora: lidera la definición de los objetivos y de la acción política. La coalición radical no presenta una estructura de poder interna muy definida. Ambas organizaciones parecen estar a un mismo nivel de poder político, aunque las centrales sindicales juegan un papel algo más importante. 


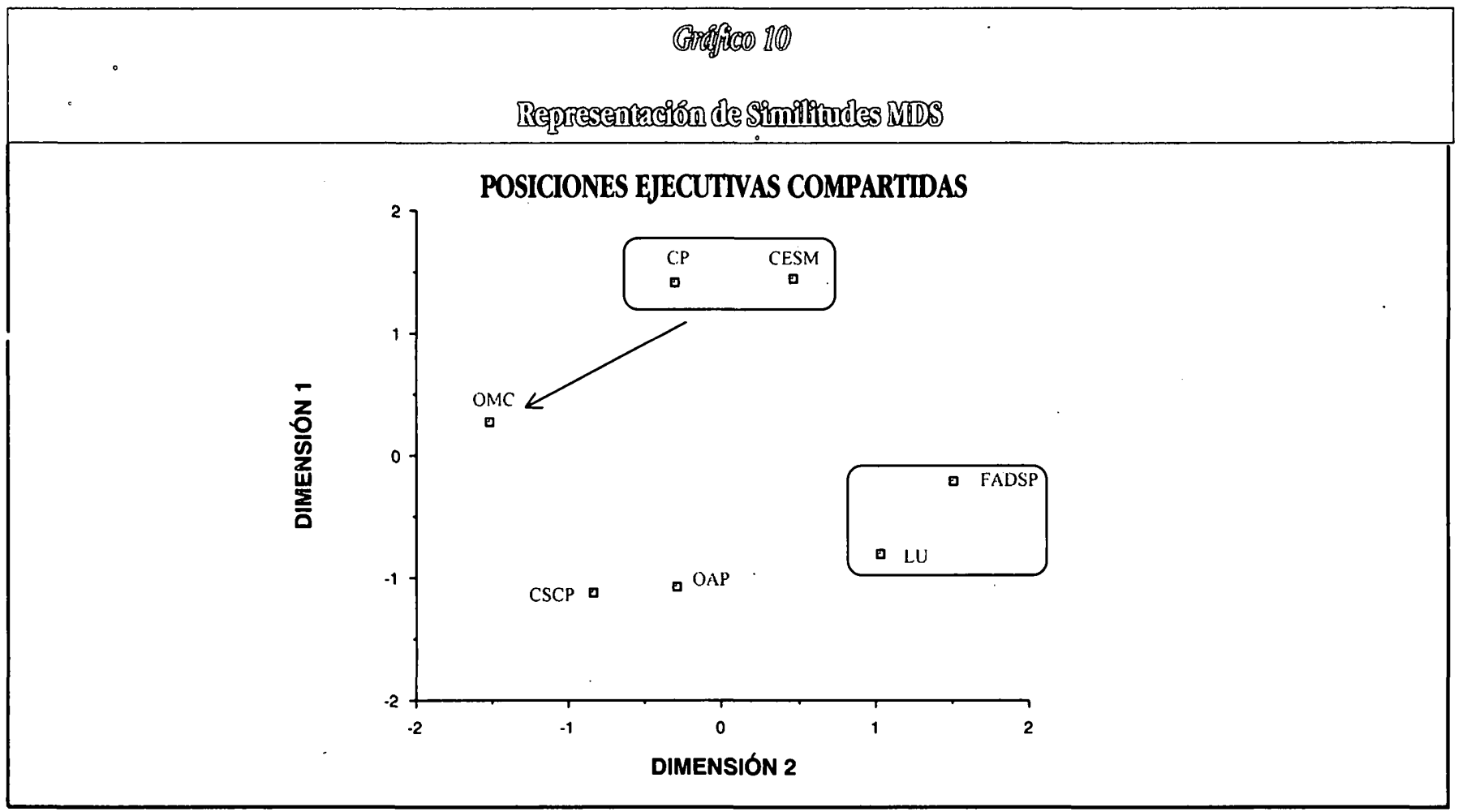

\section{MAPA DE CONTACTOS POLIITICOS MÁS FRECUENTES}

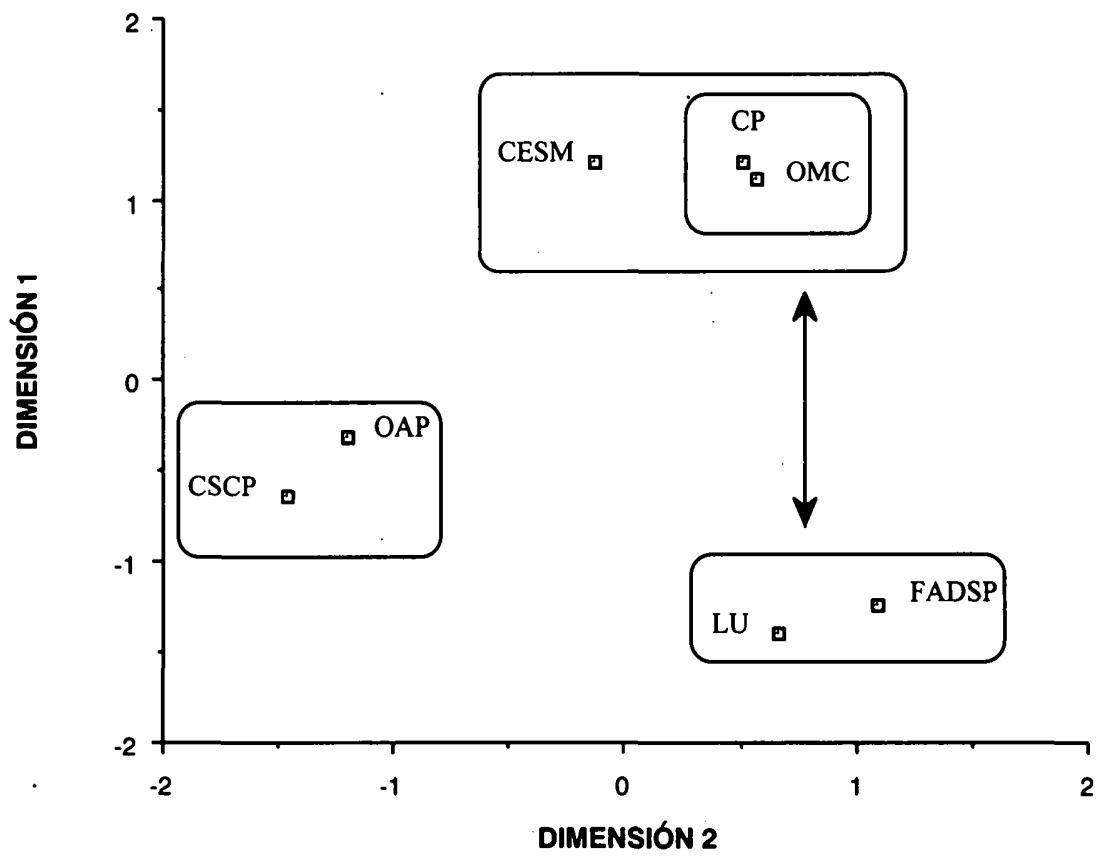




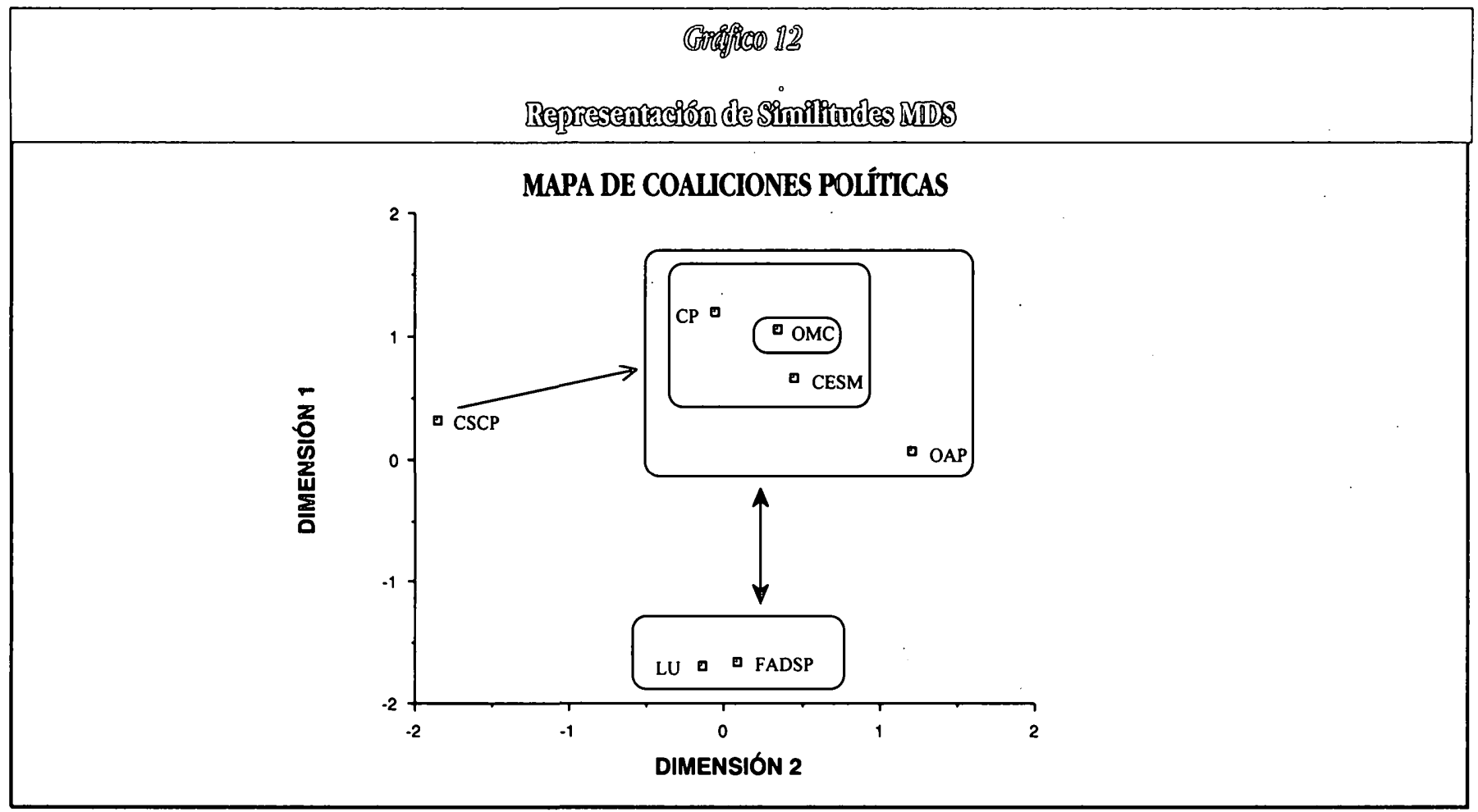

\section{Gonatureo 13}

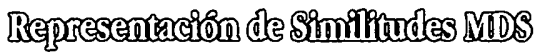

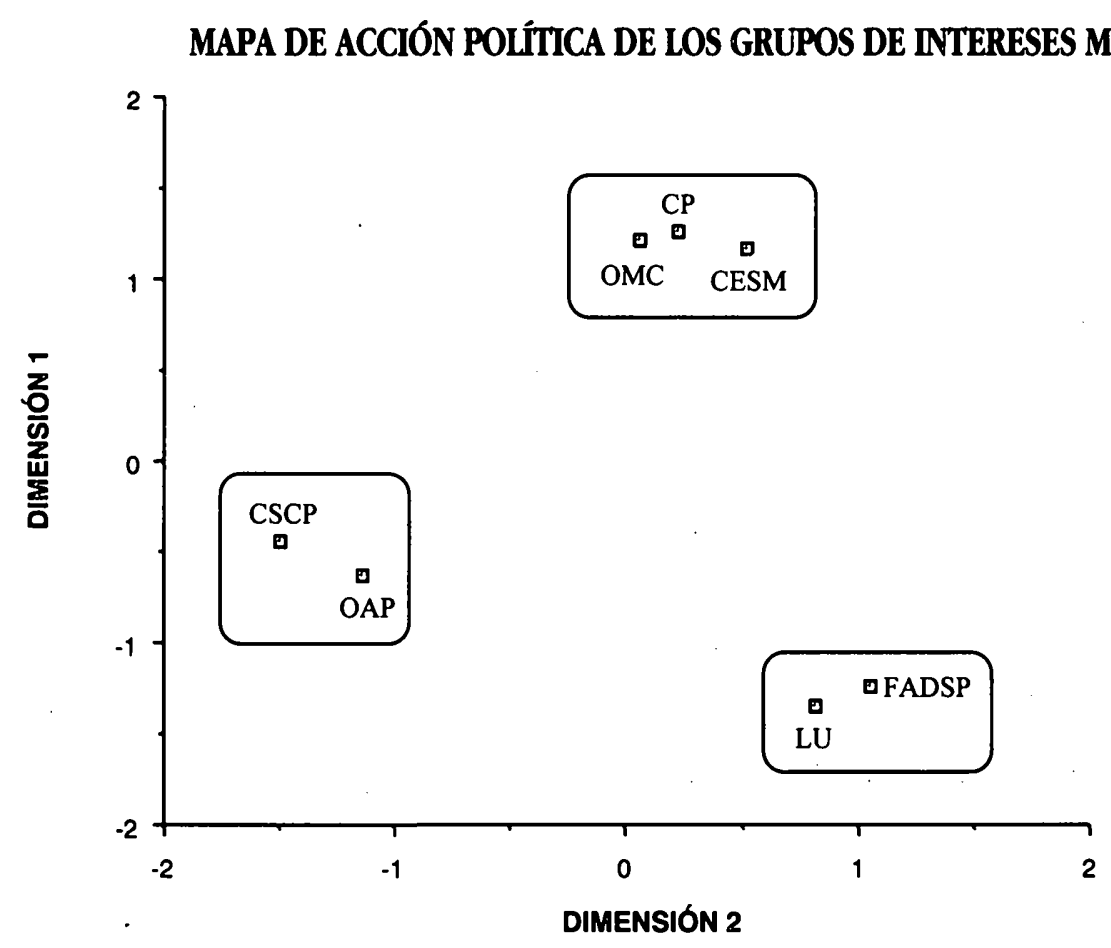

$\mathrm{RSQ}=.662$

K's STRESS= 298 


\section{Redes políticas}

El análisis de las redes políticas sanitarias sirve de complemento al análisis dimensional del complejo político sanitario. Hemos utilizado matrices relacionales de los contactos políticos más fuertes entre organizaciones, de los interlockings entre organizaciones (es decir, relaciones interorganizativas por cargos ejecutivos comunes), y de coaliciones políticas.

El Gráfico 14 muestra la red interorganizativa generada por la posesión de cargos ejecutivos comunes entre organizaciones. Coincide con el Gráfico 10 en la distribución espacial de los actores, pero avanza enormemente nuestra comprensión de esta red política al mostrar la completa interconexión de todos los actores. Ésta es una red completa, no hay actores aislados Las relaciones interorganizativas aseguran la transmisión de información política y el contacto político entre todos los actores, ya sea directa 0 indirectamente.

Cabe destacar la existencia de un colectivo altamente cohesionado formando un cliqué (estructura de relaciones directas y recíprocas entre actores), formando el centro neurálgico de la red, formado por los Colegios de Médicos (OMC y Colegios Provinciales) junto a otras Asociaciones Profesionales (OAP) y a Organizaciones de Centros Sanitarios Privados (OCSP). De este centro altamente cohesionado dependen la CESM, por un lado, y las organizaciones sindicales y la FADSP. Aquí juegan un papel fundamental de conectores de la red política las asociaciones profesionales (no Colegios) y el sector privado. Conectan al sector más conservador (OMC, Colegios Provinciales y CESM) con el sector más radical (sindicatos y FADSP). Se convierten en las organizaciones centrales de la red, que facilitan la transmisión de información y la articulación de la acción. En términos estructurales detentan el poder de esta red política, seguidas en prominencia por los Colegios de Médicos.

El Gráfico 15 muestra la estructura política formada por los contactos políticos más fuertes entre las organizaciones. Reproduce la distribución espacial que encontrábamos en el Gráfico 11 pero nos completa esa visión con la estructura relacional. Es una red completa, es decir, todos los actores están conectados a través de relaciones políticas que transmiten información, pue- den servir de elementos de negociación de conflictos y pueden articular la acción de toda la red.

\section{Grífico 14}

\section{Interloking: Lazos entre organizaciones a través de cargos ejecutivos compartidos}

Representación gráfica (con KracPlot 3.0) de la matriz relacional

1: OMC=Organización Médica Colegial-Consejo General de Colegios Oficiales de Médicos

2: CPOM: Colegios Provinciales Oficiales de Médicos

3: CESM: Confederación Española de Sindicatos Médicos

4: FADSP: Federación Española de Asociaciones para la Defensa de la Sanidad Pública

5: LU: Sindicatos (CCOO-UGT)

6: OAP: Otras Asociaciones Profesionales

7:OCSP: Organizaciones de Centros Sanitarios Privados 


\section{Grífico 15}

\section{Estructura de contactos políticos más fuertes}

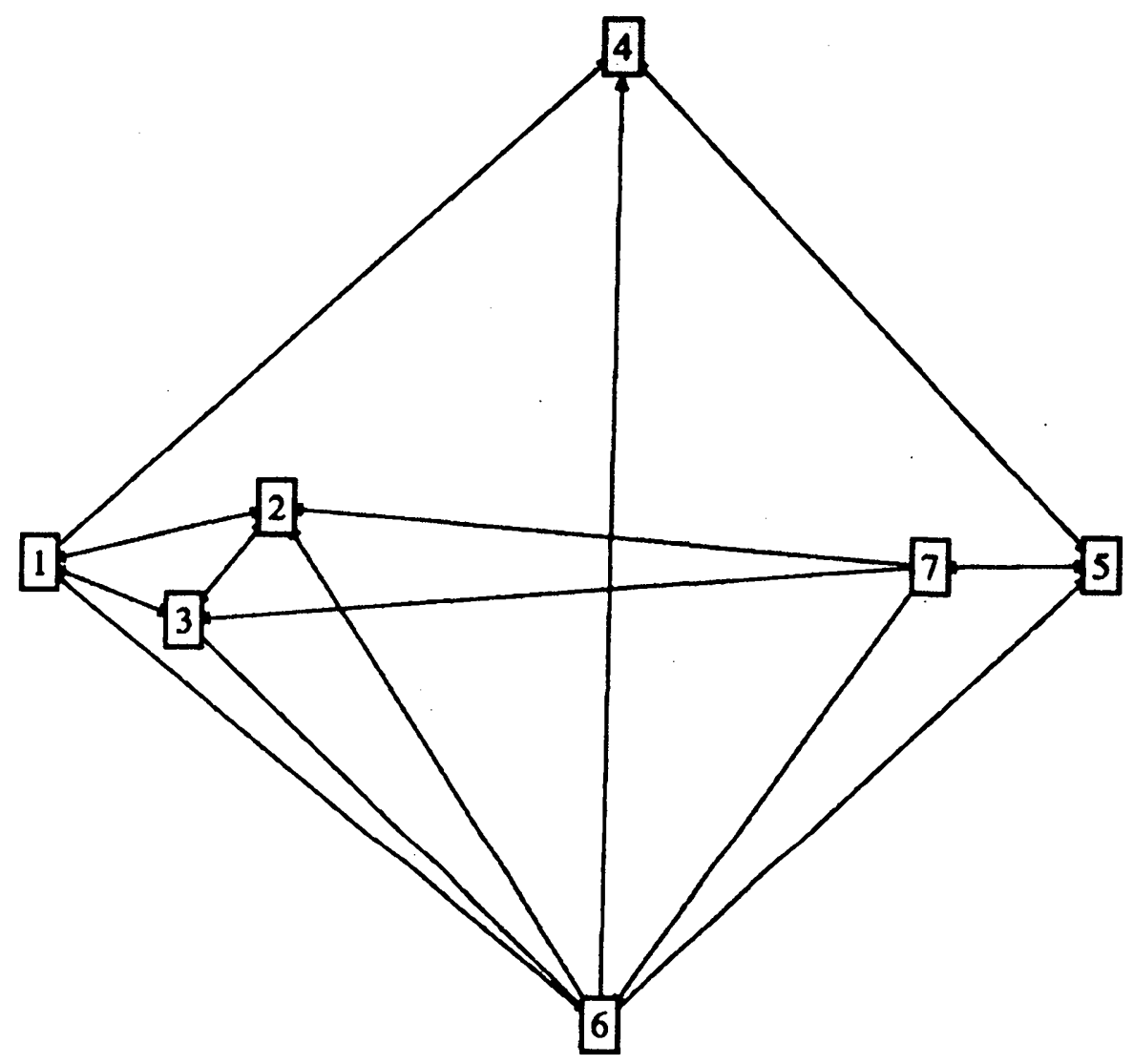

Representación gráfica (con KracPlot 3.0) de la matriz relacional

1: OMC=Organización Médica Colegial-Consejo General de Colegios Oficiales de Médicos

2: CPOM: Colegios Provinciales Oficiales de Médicos

3: CESM: Confederación Española de Sindicatos Médicos

4: FADSP: Federación Española de Asociaciones para la Defensa de la Sanidad Pública

5: LU: Sindicatos (CCOO-UGT)

6: OAP: Otras Asociaciones Profesionales

7:OCSP: Organizaciones de Centros Sanitarios Privados

La red está compuesta por la unión de dos grandes círculos sociales (resultado de la superposición de dos cliqués cada uno) formados por OMC, Colegios Provinciales de Médicos y CESM más las Asociaciones Profesionales y el sector privado (OCSP), por un lado, y los sindicatos y FADSP más las Asociaciones Profesionales y el sector privado (OCSP), por otro lado. Ambos círculos están ligados por estas dos últimas organizaciones que juegan de nuevo un papel central de cohesión e intermediación. La OMC destaca como la organización políticamente más central y prominente al ser la que más contactos políticos recibe, y los Colegios Provinciales y la CESM como las políticamente más dependientes. La red de contactos políticos, que refleja la división antes vista entre los sectores más radicales y conservadores y la cohesión en cada uno de esos conglomerados, destaca especialmente el papel clave de intermediación ju- gado por los sectores política e ideológicamente intermedios y supuestamente más débiles (OAP y OCSP) conectando todo el espacio político.

El Gráfico 16 representa la estructura de acción política conjunta, es decir, las relaciones políticas de coalición. En términos estructurales es una red completa, no hay organizaciones que no participen, en un momento u otro, en alguna coalición. De hecho, todas las organizaciones han desarrollado acciones en coalición con el resto de organizaciones. A pesar de las diferencias ideológicas y políticas, la acción política de las organizaciones de intereses sanitarios ha cristalizado en coaliciones entre todos los sectores y organizaciones. La acción política es netamente colectiva, no individual. Los sistemas interorganizativos y las relaciones políticas facilitan la acción conjunta por medio de 


\section{Gráfico 16}

\section{Estructura de coaliciones politicas}

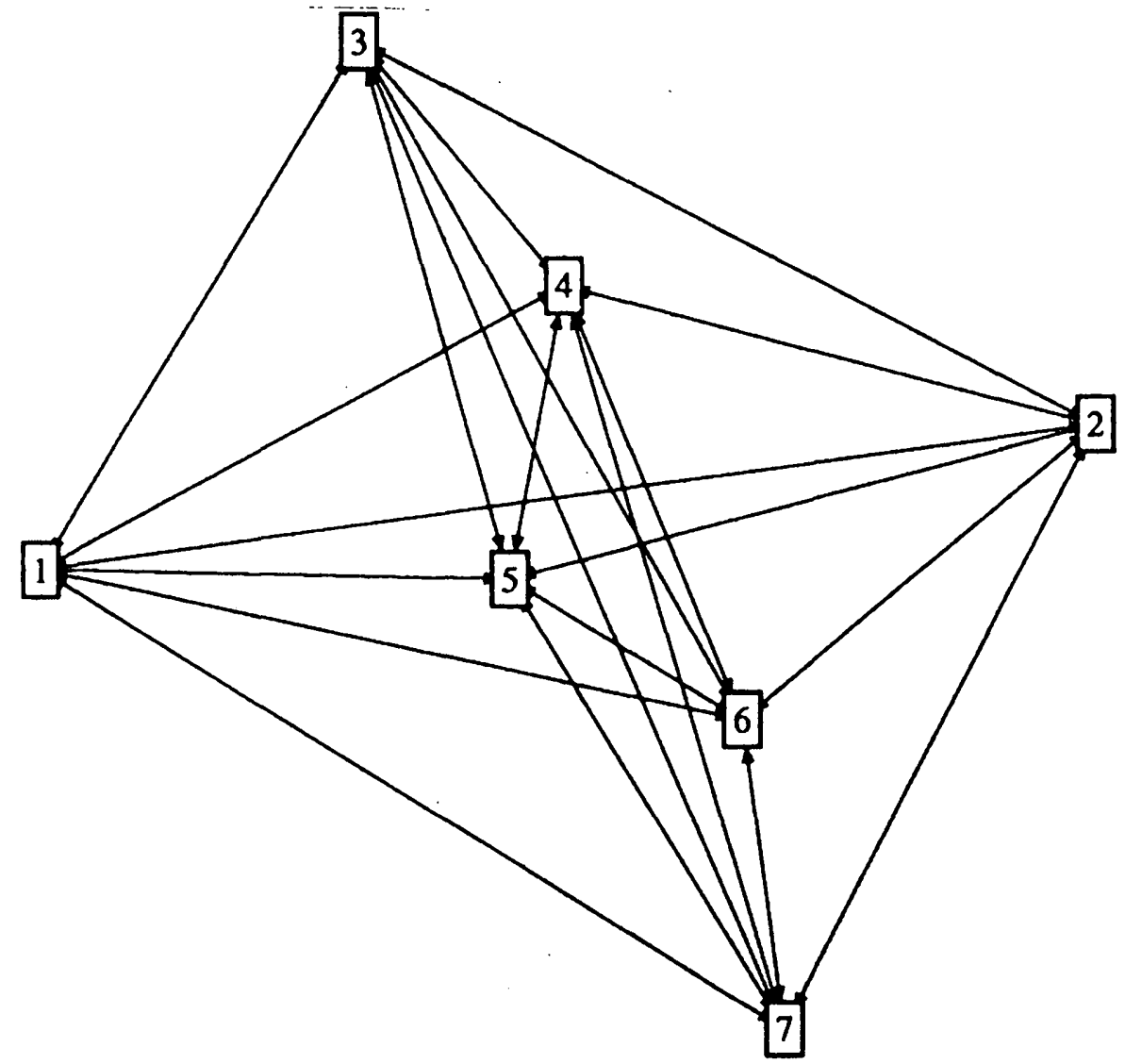

Representación gráfica (con KracPlot 3.0) de la matriz relacional

1: OMC=Organización Médica Colegial-Consejo General de Colegios Oficiales de Médicos

2: CPOM: Colegios Provinciales Oficiales de Médicos

3: CESM: Confederación Española de Sindicatos Médicos

4: FADSP: Federación Española de Asociaciones para la Defensa de la Sanidad Pública

5: LU: Sindicatos (CCOO-UGT)

6: OAP: Otras Asociaciones Profesionales

7:OCSP: Organizaciones de Centros Sanitarios Privados

coaliciones, cuya composición varía con la temática a tratar y momento político.

En esta estructura social de coaliciones destaca el papel políticamente más prominente, visible y activo de los Colegios Profesionales (OMC y Colegios Provinciales), y la mayor dependencia política de CESM. Las asociaciones profesionales (OAP) juegan de nuevo un papel clave de intermediación facilitando la coaliciones entre los sectores más radicales y los más conservadores. Poseen la llave de la acción colectiva.

La red política que emerge de estas tres estructuras relacionales pone de manifiesto elementos importantes para entender la dinámica política sanitaria: 1 . La acción política de las organizaciones de intereses no es de tipo individual sino de tipo co- lectivo. Las redes interorganizativas facilitan la acción colectiva. 2. Existe un sistema de interrelación complejo que liga todas las organizaciones del espacio político. Ello permite la transmisión de información, la negociación, la creación de confianza y como resultado la articulación de acción colectiva. 3. Quedan reflejados los sistemas estructurales basados en la proximidad ideológica y política, es decir, un conglomerado formado por los sectores más conservadores (OMC, CPOM y CESM) y otro formado por los sectores más radicales. 4. La red política es completa, es decir, todos los actores están ligados, gracias al papel clave de intermediación y conexión jugado por las organizaciones políticamente (aparentemente) más débiles e intermedias (OAP y OCSP). Ese papel de intermediación las configura como las organizaciones con el mayor poder político estructural de la 
red. 5. Destaca como políticamente más activo el conglomerado formado por los Colegios Profesionales (OMC y Colegios Provinciales) del que depende políticamente la CESM.

El campo de la política sanitaria aparece articulado en forma de red política compacta que, a la par que consolida las proximidades y diferencias ideológicas y políticas, conecta a todas las organizaciones. La red política refleja a su vez una estructura clara de poder político donde destaca la prominencia y actividad política de los Colegios Profesionales, por un lado, y el poder cohesionador estructural de las asociaciones profesionales más pequeñas y del sector privado. En esa estructura de poder, la CESM está en una situación de dependencia con respecto de los Colegios Profesionales, y las organizaciones más radicales en una posición de mayor marginalidad.

- Catedrático de Sociología. Departamento de Sociología y Análisis de las Organizaciones. Universidad de Barcelona

\section{Bibliografia}

M. ALCOBER, R. CABELLO, Participación de los grupos profesionales y no profesionales en la gestión y resolución de problemas sanitarios y de la Seguridad Social., Revista de Seguridad Social 4, 1979.

R. AXELROD (ed.), Structure of Decision: The Cognitive Maps of Political Elites (PrinceIon: Princeton University Press, 1976).

S. BERGER (ed.), Organizing Interests in Western Europe: pluralism, corporatism, and the transformation of politics (Nueva York: Cambridge University Press, 1981).

P. BIrnibum, The State versus Corporatism, Politics and Society 11(4):477-501 (1982)

J. BRand, Doctors and ibe State: The British Medical Profession and Government Action in Public Healib (Baltimore: Johns Hopkins University Press, 1965).

T. Brante, Professional types as a strategy of analysis, en M. BURRAGE, R. TORSTENDAHL (eds.) Professions in Theory and History (Londres: Sage, 1990).

R. BuRT, Toward a Structural Theory of Action (Nueva York: Academic Press, 1982); Structural Holes: The Social Structure of Competition (Londres: Harvard University Press, 1992); con M. Minor, Applied Network Analysis (California: SAge, 1983).

A. CAwson (ed.), Organized Interests and the State: Studies in Meso Corporatism (Beverly Hills, CA: Sage, 1985); Corporatism and Political Theory (Nueva York: Blackwell, 1980).

R. COTARELO, Transición política y consolidación democrática. España (1975-1986) (Madrid: CIS, 1992).

A. Cox, N. O'Suluvan, The Corporate State: Corporatism and the State Tradition in Westem Europe (Brookfield: Gower, 1988).

M. Crozier, E. Friedberg, Actors and Systems: The Politics of Collective Action (Chicago: Chicago University Press, 1980).

J.E. CHUBB, Interest Groups and the Bureaucracy (Stanford, CA: Stanford University Press, 1983).

H. ECKSTEIn, Pressure Groups Politics: The Case of the British Medical Association (Stanford: Stanford University Press, 1960); The English Healtb Service (Cambridge: Harvard University Press, 1958).
S. GINer, M. PÉrez Yruela (eds.), El corporatismo en España (Barcelona: Ariel, 1988); La sociedad corporativa (Madrid: CIS, 1979).

R. GoulD, Collective Action and Network Structure. American Sociological Review 58 (1993).

J.R. HOLINGGWORTH, J, HAGE, R.A. HONNEMAN, State Intervention in Medical Care (Ithaca: Comell University Press, 1990).

I.R. Hoss, System Analysis in Public Policy: A Critique (Berkeley: University of California Press, 1972).

E. INMERGUT, Health Politics, Interest and Institutions in Western Europe (Nueva York: Cambridge University Press, 1993); $\cdot$ Health care policies and professionals associations: A comparative perspective, presentado en New Institutionalism: State, Society and Economy, Council for Eumpean Studies Workshop, University of Colorado 1990.

T. Johnson, G. LaRKIn, Y M. SAKS (eds), Health Professions and the State in Europe (Londres: Routledge, 1993).

P.R. JONES, Doctors and the BMA (Londres: Gower, 1981).

J. KEAVE, Civil Society and the State (Londres: Verso, 1988).

J.W. Kingdon, Agendas, Alternatives and Public Policies (Boston: Litlle, Brown and Co., 1984).

R. KLEIN, $\cdot$ The corporate state, the health service and the professions', New University Quartely (Spring 1977), pp. 163-180.

R. KLEIN, The Politics of the National Health Service (Londres: Longman, 1983).

D. Kvoke, Organizing for Collective Action (Nueva York: Aldine de Gruytetr, 1990); Political Networks: The Structural Perspective (Nueva York: Cambridge University Press, 1990); con J. KukLINsw, Network Analysis (Califomia: SAge, 1982).

J.B. KRUSKAL, M. WISH, Multidimensional Scaling (Beverly Hills, CA: Sage, 1978).

J. Lapalombara, Interest Groups in Italian Politics (Princeton, NJ: Princeton University Press, 1964).

C.G. LATHROP, Hiddens Hierarchies: The Professions and Government (New York: Harper and Row, 1960). 
E. Laumav, D. Kvoke, The Organizational State: Social Change in National Policy Domains (Madison, WI: University of Wisconsin Press, 1987).

E. Lauman, F. PapPI, Networks of Collective Action (Nueva York: Academic Press, 1976).

G. LeHMBRUCH, P. SChMITTER (eds.), Patters of Corporatist Policy Making (Beverly Hills, CA: Sage, 1982).

J. J. LuNZ, El sistema de partidos en España (Madrid: Narea, 1976); •An Authoritarian Regime: The Case of Spain en E. Allardo y S. RoKkan, Mass Politics: Studies in Political Sociology (Nueva York: Free Press, 1979);; La realidad asociativa de los españoles. en Confederación Española de Cajas de Ahorros (eds.), Sociologia española de los años setenta (Madrid: CECH, 1971); A Century of Politics and Interests in Spain. en Berger, S.D. (ed.), Organizing Interests in Western Europe (Nueva York: Cambridge University Press, 1981); - Transitions to Democracy•, The Washington Quarterly 13:143164 (1990).

J. LINZ, F. ORIZO, y GOMEZ REINO, Informe sociológico sobre el cambio político en España 1975-1981 (Madrid: FOESSA, 1982).

B. MARIN y R. MAYnTz (eds.) Policy Networks (Boulder, Colorado: Westviw Press, 1991).

J.M. de MIGUEL, :The Spanish health planning experience 1964-1975, Social Science and Medicine 9:451-459 (1975)); con M. GUILLÉN, .The case of Spain. en M. FIELD (ed.), Crass National Studies of Health Care Systems (Londres: Tavistok, 1987); con M. PORTA y J.A. RODriguez, Socialist health policies and politics in Spain. en G. AlBRECHT, Advances in Medical Sociology (Greenwich, CT: Jai Press, 1990).

M. MIzRUCHI, The Structure of Corporate Political Action (Cambridge: Harvard University Press, 1992).

T.M. MOE, The Organization of Interests: Incentives and the Internal Dymamics of Political Interest Groups (Chicago: Chicago University Press, 1980).

C. OFFe, The attribution of public status to interest groups: Observations on the west german case- en S. BERGER (ed.), Organizing Interests in Western Europe: pluralism, corporatism, and the transformation of politics (New York: Cambridge University Press, 1981).

M. OLSON, The Logic of Collective Action (Cambridge, MA: Harvard University Press, 1965).

Organización Médica Colegial, Dos años de relaciones con la Administración: Informes, propuestas y documentas alternativos a los proyectos normativos del gobierno (Madrid: Consejo General de Colegios Oficiales de Médicos, 1985).

V. PÉrez Díaz, •Médicos, administradores y enfermos, Papeles de Economía Española 12-13 :231-251 (1982); Economic policies and social pacts in Spain. en I. Scholten (ed.), Political Stability and Neo-Corporatism: Corporatist Integration and Social Cleavages in Western Europe (Beverly Hills, CA: Sage, 1987); El retormo de la sociedad civil (Madrid: Instituto de Estudios Económicos, 1987).

R. PERRUCCI. y H. POTTER, (ed.), Networks of Power (Nueva York: Aldine de Gruyter, 1989).
J. RoCA, Neo-corporatism in post Franco Spain. en I. Scholten (ed.), Political Stability and Neo-Corporatism: Corporatist Integration and Social Cleavages in Western Europe (Beverly Hills, CA: Sage, 1987).

Josep A. RoDRiGUEZ, El poder de la corporación: El caso de la profesión médica española. en S. GINer, M. PÉRez YRUELA (eds.), El corporatismo en España (Barcelona: Ariel, 1988); :La política de las organizaciones de intereses médicos. REIS 59, 1992; The Politics of Medicine in Spain (New Haven: Yale University, 1991). Análisis estructural y de redes (Madrid: CIS, Colección de Cuademos Metodológicos, 1995). •Nuevas formas de política y de poder. en B. OLTRA (ed.) Sociedades, civilizaciones y culturas mediterráneas (Alicante: FCCSS y MM, 1999). El círculo del poder en Revista Española de Investigaciones Sociológicas (en revisión 1999), y en Documents de Treball, Universitat de Barcelona (en prensa, 1999). .Intereses profesionales. en $V$ Informe FOESSA, capítulo de Sanidad (Madrid: Fundación FOESSA, 1995). The Politics of the Spanish Medical Profession. en JoHnson, LaRKIN, SAKS Health Professions and the State (London: Routledge, 1994). The Politics of Health Policy Reform in Spain. en Richard Gunther (ed.) Politics, Society, and Democracy: The Case of Spain. Essays in Honor of Juan J. Linz (Oxford: Westwiew Press, 1993), con Jesús M. de Miguel.

S. SCHIFFMAv et al, Introduction to Multidimensional Scaling (Nueva York: Academic Press, 1981).

P. SCHMITTER, Models of Interest Intermediation and Models of Societal Change in Westem Europe, Comparative Political Studies 10:7-38 (1977); •Neo-corporatism and the State en W. GRANT (ed.), The Political Economy of Corporatism (Nueva York: St. Martin's Press, 1985); con G. LeHMBRuCH (eds.), Trends in Corporatist Intermediation (Beverly Hills, CA: Sage, 1979);

J. SCoTT, Social Network Analysis: A Handbook (Califomia: Sage, 1991).

W.E. STESLICKE, Doctors in Politics: The Political Life of the Japan Medical Association (Nueva York: Praeger, 1973).

F. STOKMan et al., Networks of Corporate Power (Cambridge: Polity, 1985).

F.J. Thompson, Health Policy and the Bureaucracy: Policies and Implementation (Boston: MIT Press, 1981).

M. Useem, The Inner Circle (Nueva York: Oxford University Press, 1984).

S. WASSERMA:V, y K. FAUST, Social Network Analysis (Nueva York: Cambridge University Press, 1994):

B. Weluman y S. Berkowtz, Social Structures: A Network Analysis (Nueva York: Cambridge University Press, 1988).

H. WHTtE, Identity and Control: A Stmuctural Theory of Action (New Jersey: Princeton University Press, 1992)

H. WIARDA, From Corporatism to Neo-syndicalism: The State, Organized Labor and the Cbanging Industrial Relations in Southern Europe (Cambridge, MA: Center for European Studies, Harvard University, 1981).

F. VILLACORTA Bavos, Profesionales y burócratas: Estado y poder corporativo en la España del siglo XX, 1890-1923 (Madrid: Siglo XXI de España Editores, 1989).

D. WILSFORD, Doctors and the State: The Politics of Health Care in France and the United States (Durham, Duke University Press, 1991).

S. WoHL, The Medical Insdustrial Complex (Nueva York: Harmony Books, 1984). 